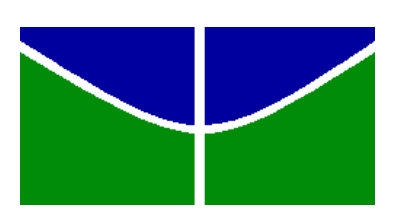

UNIVERSIDADE DE BRASÍLIA

Centro de Excelência em Turismo

Pós-graduação Lato Sensu

Curso de Especialização em Qualidade em Alimentos

\title{
APROVEITAMENTO INTEGRAL DOS ALIMENTOS: QUALIDADE NUTRICIONAL E ACEITABILIDADE DAS PREPARAÇÕES
}

Juliana Tavares Nunes

Raquel Braz Assunção Botelho 


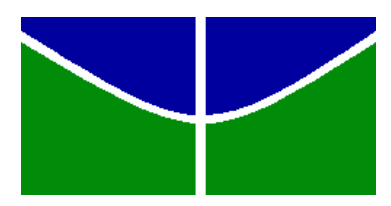

UNIVERSIDADE DE BRASÍLIA

Centro de Excelência em Turismo

Pós-graduação Lato Sensu

Curso de Especialização em Qualidade em Alimentos

\title{
APROVEITAMENTO INTEGRAL DOS ALIMENTOS: QUALIDADE NUTRICIONAL E ACEITABILIDADE DAS PREPARAÇÕES
}

\author{
Juliana Tavares Nunes \\ Raquel Braz Assunção Botelho
}

Monografia apresentada ao Centro de Excelência em Turismo - CET, da Universidade de Brasília - UnB, como requisito parcial à obtenção do grau de Especialista em Qualidade de Alimentos.

Brasília - 2009 
Nunes, Juliana, Tavares.

Aproveitamento integral dos alimentos: qualidade nutricional e aceitabilidade das preparações / Juliana Tavares Nunes - Brasília, 2009.

$64 \mathrm{f}$.

Monografia (especialização) - Universidade de Brasília, Centro de Excelência em Turismo, 2009.

Orientadora: Profạ. Drª. Raquel Braz Assunção Botelho.

1. Alimento. 2. Desperdício. 3. Saudável. I. Título. II. Título: qualidade nutricional e aceitabilidade das preparações. 


\title{
UNIVERSIDADE DE BRASÍLIA \\ Centro de Excelência em Turismo \\ Pós-graduação Lato Sensu
}

Curso de Especialização em Qualidade em Alimentos

Monografia apresentada ao Centro de Excelência em Turismo - CET, da Universidade de Brasília - UnB, como requisito parcial à obtenção do grau de Especialista em Qualidade em Alimentos.

\section{APROVEITAMENTO INTEGRAL DOS ALIMENTOS: QUALIDADE NUTRICIONAL E ACEITABILIDADE DAS PREPARAÇÕES}

\author{
Juliana Tavares Nunes
}

Aprovado por:

Professora orientadora: Dra ${ }^{\mathrm{a}}$ Raquel B. A. Botelho

Professor MSc. Luiz Antonio Borgo

Professora Dr ${ }^{\mathrm{a}}$. Wilma Maria Coelho Araújo

Brasília, 30 de Março de 2009. 


\section{DEDICATÓRIA}

Dedico esse trabalho, em primeiro lugar, ao Senhor Jesus, pois até aqui Ele tem me ajudado e, em segundo, aos meus pais, avós e noivo por mais uma vitória alcançada. 


\section{AGRADECIMENTOS}

Agradeço ao Senhor Jesus, pois durante toda a minha caminhada a sua presença tem sido real e impactante, me fortalecendo e me dado ânimo a cada dia da minha existência. Aos meus pais, Ailton e Idenir que com a simplicidade me ensinaram a vencer dia a pós dia sem me prender aos obstáculos. Aos meus avôs, Jurandy e Edna que me ensinaram a andar no caminho da verdade, do amor e da sabedoria acreditando em mim e na minha vitória. Ao meu noivo, que mesmo distante, permaneceu mais do que eu presente nos meus dias. Aos meus amigos e

amigas pelo carinho e apoio. Á minha orientadora Raquel Botelho, que com base na sua experiência como professora e doutora, forneceu-me orientações, sugestões e dicas sobre a construção deste estudo. Aos meus professores, mestres e doutores que através dos seus brilhantes ensinamentos contribuíram para mais uma vitória alcançada na minha trajetória. A todos, Deus os abençoe hoje e sempre. 


\section{EPÍGRAFE}

O desperdício, sintoma de um país sem marcas dramáticas em sua história, é um sério problema na produção e distribuição de alimentos. Principalmente nos países subdesenvolvidos ou em desenvolvimento, o desperdício é ainda um problema a ser resolvido, assim como muitos outros problemas de estrutura, condicionado por fatores culturais.

Renata Borges (1991) 


\section{RESUMO}

A falta de informações sobre os princípios nutritivos e o aproveitamento dos alimentos gera desperdício de toneladas de recursos alimentares. Por meio do aproveitamento integral dos alimentos é possível combater essa situação, pois o mesmo utiliza casca, talo, folha, polpa e semente dos alimentos e é indicado para toda população. Com isso reduz-se o desperdício, o gasto com alimentação, melhora-se a qualidade nutricional da preparação e sua diversificação, pois em muitos alimentos o teor de nutrientes da parte não convencional é maior em relação à polpa. Com o objetivo de avaliar a aceitabilidade das preparações padrões e modificadas, foram desenvolvidas quatro receitas: bolo de banana, bolo de casca de banana, suco de acerola e suco de acerola, cenoura e couve, para serem provadas pelos alunos do pré-vestibular localizado em Vitória no Espírito Santo. Cada aluno foi solicitado a responder um questionário de aceitabilidade, onde foram analisadas as seguintes variáveis: faixa etária, sexo, renda, município, ocupação, além de alguns hábitos como os de cozinhar em casa, quem prepara os alimentos, custo das receitas, escalas de aceitação dos bolos e dos sucos e a identificação dos seus ingredientes. Os resultados mostraram que as preparações obtiveram bons percentuais de aceitação, porém os bolos foram mais aceitos em relação aos sucos. O suco com aproveitamento integral ainda precisa melhorar a forma de preparo para agradar a clientela alvo. Conclui-se, que há necessidade de desenvolver trabalhos, pesquisas, tabelas com dados sobre o valor nutricional das partes dos alimentos que costumam ser desprezadas.

Palavra chave: Alimento, Desperdício, Saudável. 


\begin{abstract}
The lack of information on the nutritional principles and the exploitation of foods generate wastefulness of tons of alimentary resources. Through the integral exploitation of foods it is possible to fight this situation, therefore the same it uses rind, stem, leaf, pulp and seed of foods and is indicated for all population. With this it reduces wastefulness, the expense with feeding, improves the nutricional quality of the preparation and diversifies the same ones, therefore in many foods the content of nutrients of the not conventional part is bigger in relation to the pulp. With the objective to evaluate the acceptability of the modified preparations standards, four prescriptions had been developed: cake of banana, cake of banana rind, juice of Barbados cherry and juice of Barbados cherry, carrot and kale, to be proven for the students of the daily pay-vestibular contest located in Victory in the Espirito Santo. Each student was submitted to answer an acceptability questionnaire, where the following variable had been analyzed: age bracket, sex, income, city, occupation, beyond some habits as to cook in house, who prepares foods, cost of prescriptions, scales of acceptance of cakes and juices and the identification of the ingredients of the same ones. The results had shown that the preparations had gotten good percentages of acceptance; however the cakes had been more accepted in relation to juices. The juice with integral exploitation still needs to improve the preparation form to please the white clientele. I concluded that is necessary to develop works, research, tables with data on the nutritive value of the parts of the foods that use to be rejected.
\end{abstract}

Keywords: Food, Wastefulness, Healthful. 


\section{LISTA DE FIGURAS}

Figura 1. Percentual de aceitação do bolo de banana e do bolo de casca de banana. Vitória 2008 36

Figura 2. Percentual de aceitação do suco de acerola e o suco de acerola, cenoura e couve. Vitória 2008 36

Figura 3. Frequência de provadores (\%) segundo o custo (em reais) do bolo de banana e o bolo de casca de banana, estimado pelos os mesmos. Vitória, 2008

Figura 4. Frequência de provadores (\%) segundo o custo (em reais) do suco de acerola e o suco de acerola, cenoura e couve, estimado pelos os mesmos. Vitória, 2008 


\section{LISTA DE TABELAS}

Tabela 1 - Características sócio-demográficas dos alunos participantes. Vitória 2008:

Tabela 2 - Caracterização do Perfil dos Degustadores. Vitória 2008:

Tabela 3 - Identificação dos provadores em relação aos ingredientes das preparações. Vitória 2008: 38

Tabela 4 - Distinção dos provadores referente às receitas - padrão. Vitória 2008:

Tabela 5 - Distinção dos provadores referente às receitas modificadas. Vitória 2008: 


\section{LISTA DE ABREVIATURAS E SIGLAS}

IDR: Ingestão Diária Recomendada

INAN: Instituto Nacional de Alimentação e Nutrição

SESC: Serviço Social do Comércio

SESI: Serviço Social da Indústria

PAA: Programa de Aquisição de Alimentos

UAN: Unidades de Alimentação e Nutrição

IBGE: Instituto Brasileiro de Geografia e Estatística

OMS: Organização Mundial de Saúde

g: gramas 
1 INTRODUÇÃO

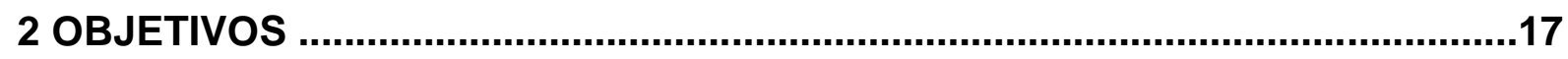

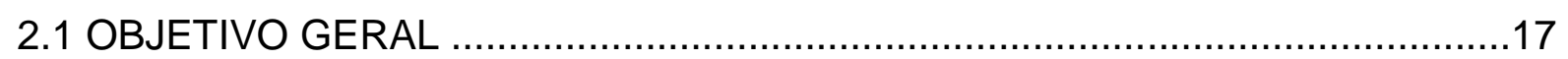

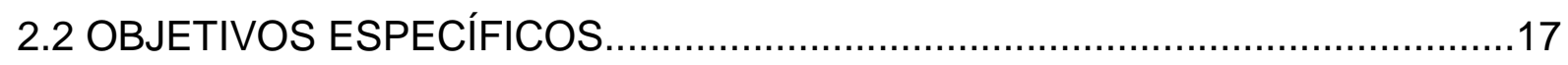

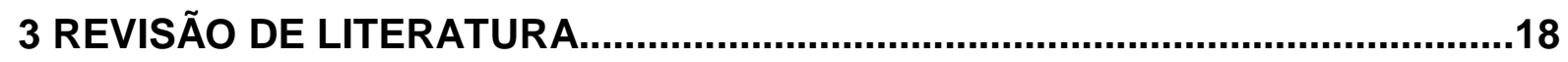

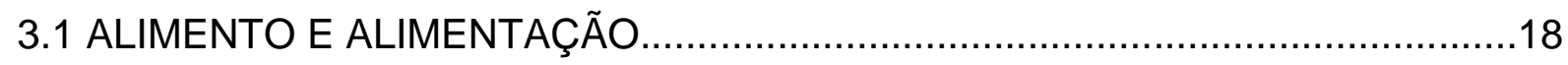

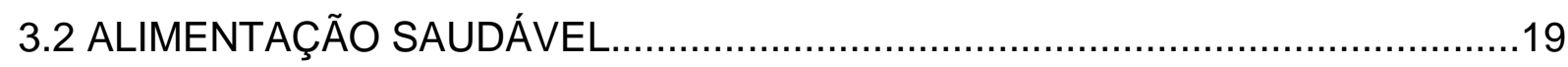

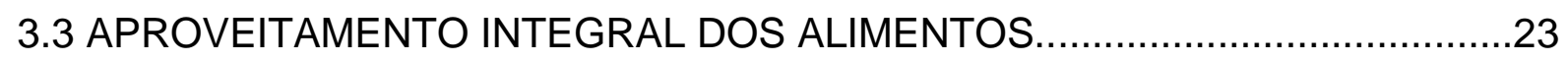

3.4 PROGRAMAS QUE INCENTIVAM O APROVEITAMENTO INTEGRAL DOS

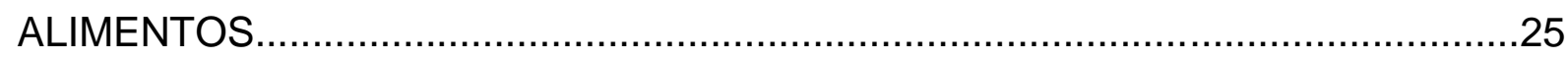

3.5 A IMPORTÂNCIA DAS PARTES NÃO CONVENCIONAIS DOS ALIMENTOS...27

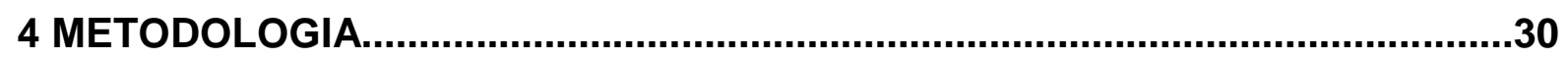

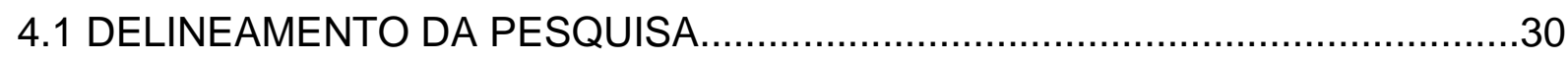

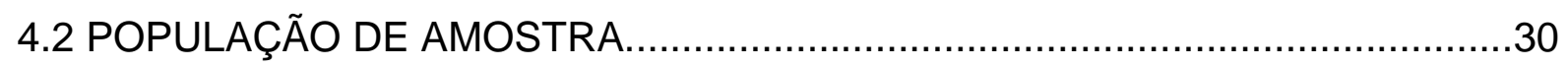

4.3 DESENVOLVIMENTOS DAS RECEITAS.....................................................

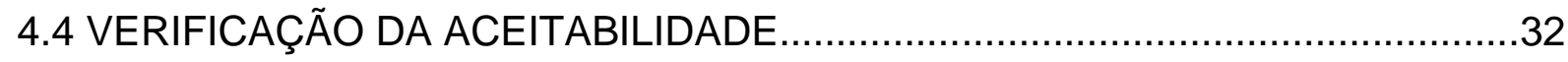

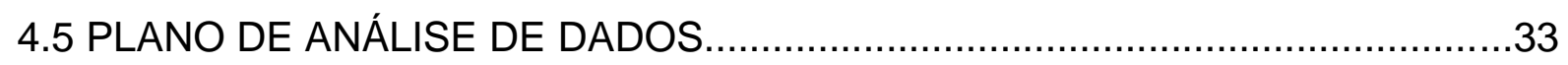

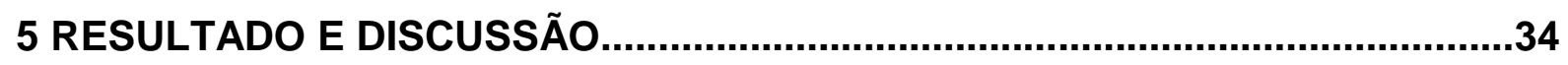

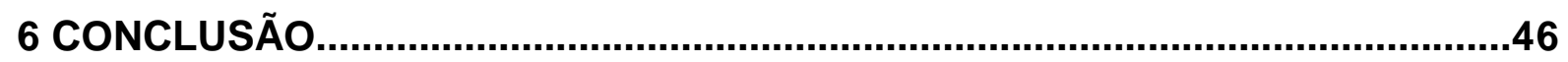

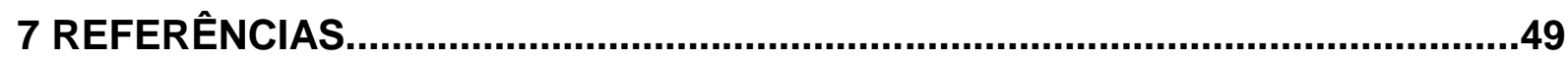

APÊNDICE I - TERMO DE CONCORDÂNCIA DE PARTICIPAÇÃO DA

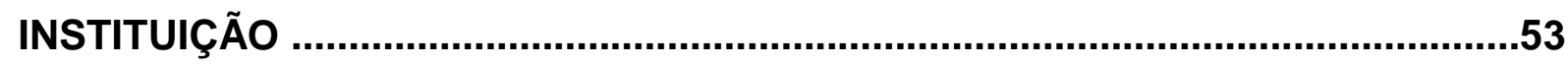

APÊNDICE II - INFORMATIVO DO PROJETO...............................................54 
APÊNDICE III - TERMO DE CONSENTIMENTO LIVRE ESCLARECIDO . .55

APÊNDICE IV - FICHA TÉCNICA DO BOLO DE BANANA ..................................56

APÊNDICE V - FICHA TÉCNICA DO BOLO DE CASCA DE BANANA..................57

APÊNDICE VI - FICHA TÉCNICA DO SUCO DE ACEROLA...............................58

ANEXO VII - FICHA TÉCNICA DO SUCO DE ACEROLA, CENOURA E COUVE. .59

APÊNDICE VIII - QUESTIONÁRIO DE ACEITABILIDADE..................................60

APÊNDICE IX - INFORMATIVO DO BOLO DE BANANA.....................................61

APÊNDICE X - INFORMATIVO DO BOLO DE CASCA DE BANANA....................62

APÊNDICE XI - INFORMATIVO DO SUCO DE ACEROLA....................................63

APÊNDICE XII - INFORMATIVO DO SUCO DE ACEROLA, CENOURA E COUVE. 


\section{INTRODUÇÃO}

Os dois maiores problemas que o Brasil enfrenta são a fome e o desperdício de alimentos, constituindo-se em um dos paradoxos do país, pois o mesmo produz 140 milhões de toneladas de alimentos por ano e é um dos maiores exportadores de produtos agrícolas do mundo. Ao mesmo tempo, existem milhões de pessoas excluídas, sem acesso ao alimento em quantidade e/ou qualidade (GONDIM et al., 2005).

A maior parte do lixo brasileiro é orgânico, ou seja, restos de alimentos. Esse fato traz à tona um dos maiores problemas da sociedade de consumo, que é a má utilização dos recursos alimentares e seu consequente desperdício (SESI, 2004).

As constantes crises econômicas enfrentadas atualmente pelo Brasil refletem diretamente nas camadas sociais menos favorecidas, que encontram dificuldades para adquirir alimentos em quantidade e qualidade satisfatórias (MALUF et al., 1996). Esta parcela da população tem pouca informação sobre o valor nutritivo das frutas, hortaliças, carnes e grãos. São pessoas que poderiam aproveitar melhor os produtos tirando deles o máximo proveito. Mas, como não têm acesso às informações claras, desconhecem a forma adequada de preparo, não aproveitam o máximo dos alimentos e geram desperdício que se apresenta como um grande problema na produção, distribuição, comercialização e preparo dos alimentos (CASOTTI et al., 1998).

Nas economias mercantis, em geral, o acesso diário aos alimentos depende, essencialmente, do poder aquisitivo, isto é, dispor de renda para comprar os alimentos. Uma parte da sociedade brasileira possui seus rendimentos abaixo do considerado ideal; tal condição restringe principalmente a alimentação que vai á 
mesa de muitas famílias brasileiras gerando, assim, uma situação de insegurança alimentar (HOFFMANN, 1994).

O aproveitamento integral dos alimentos é a utilização de um determinado alimento na sua totalidade. A falta de informações sobre os princípios nutritivos e o aproveitamento dos alimentos gera o desperdício de toneladas de recursos alimentares. Por meio do aproveitamento integral dos alimentos é possível combater essa situação, pois o mesmo utiliza casca, talo, folha, polpa e sementes; com isso diminui os gastos com alimentação, reduz-se o desperdício de alimentos e melhorase a qualidade nutricional da preparação, pois para muitos alimentos o teor de nutrientes na casca ou nos talos é maior em relação à polpa de alguns alimentos (GONDIM et al., 2005).

O princípio básico da alimentação integral é a diversidade dos alimentos, complementação das refeições, aproveitando com isso o máximo possível da casca, sementes, talos e folhas, sendo o mesmo de baixo custo ou não, gerando assim redução no custo da preparação (BANCO DE ALIMENTOS, 2003ª).

No Brasil, iniciou-se o uso do aproveitamento integral dos alimentos no combate à fome e às deficiências nutricionais de forma muito discreta. Com o passar do tempo e com as experiências adquiridas via da utilização integral, este trabalho estendeu-se por todo o país. Organizações governamentais, não governamentais e um grande número de profissionais se mobilizaram para divulgar e desenvolver esse conceito (FURTUNATO, 2007).

Para os brasileiros, a década de 80 foi o marco inicial para o crescimento e a prática do aproveitamento integral de alimentos no combate á fome e á desnutrição no país, principalmente para os grupos mais vulneráveis aos desníveis sociais como crianças e gestantes. O poder da alimentação e seus benefícios se constituem em 
um verdadeiro instrumento colocado á disposição para ajudar as classes mais carentes da população, onde o acesso a uma alimentação adequada tem sido cada vez mais difícil (SANTOS et al., 2001).

É importante destacar que essa pesquisa sobre o aproveitamento integral dos alimentos é fundamental, pois, por meio dela, é possível conscientizar a população a utilizar os alimentos na sua totalidade, evitando o desperdício e proporcionando o aumento do valor nutricional da preparação. $O$ aproveitamento integral dos alimentos não é só indicado para a população de baixa renda mas também para toda a população, pois por meio dela é possível encontrar saúde de forma econômica, diminuindo assim o gasto com a alimentação.

O presente trabalho é dividido em 6 capítulos, onde no primeiro consta a introdução, no segundo objetivo, no terceiro revisão de literatura, no quarto a metodologia, no quinto o resultado e a discussão e no sexto a conclusão. 


\section{OBJETIVO}

\subsection{OBJETIVO GERAL}

Verificar a aceitabilidade de preparações com e sem a utilização integral dos alimentos.

\subsection{OBJETIVOS ESPECÍFICOS}

Desenvolver receitas utilizando os alimentos integralmente.

Comparar a aceitabilidade das preparações - padrão com as modificadas.

Avaliar a composição nutricional das preparações por meio de tabelas de alimentos. 


\section{REVISÃO DE LITERATURA}

\subsection{Alimento e Alimentação}

As definições técnicas encontradas para a palavra alimento são amplas. Alimento quer dizer qualquer substância, podendo ela ser processada, semiprocessada ou crua que tem a finalidade de ser destinada ao consumo humano. A bebida, goma de mascar e qualquer substância que tenha sido usada na fabricação, preparo ou tratamento de alimento incluem-se na definição de alimento, porém os cosmético, tabaco ou substâncias usadas somente como drogas não se inclui nessa classificação (FAO/WHO, 1991).

O alimento é considerado como toda a substância ou mistura de substâncias, podendo ser no estado sólido, líquido, pastoso ou qualquer outra forma adequada para o consumo humano, com o objetivo de proporcionar ao organismo humano os nutrientes necessários para a sua formação e desenvolvimento (BRASIL, 1969).

Substâncias ou misturas que fornecem nutrientes imprescindíveis para a formação, manutenção e desenvolvimento no organismo humano são denominados como alimentos (BRASIL, 2008).

A palavra alimento significa uma substância que tem a finalidade de promover o crescimento e a produção de energia necessária para as diferentes funções do organismo humano (FERREIRA, 2005).

A alimentação é fundamental para o ser humano desde o nascimento, pois por meio dela é possível extrair nutrientes importantes dos alimentos, sendo esses, proteínas, carboidratos, lipídeos, vitaminas e sais minerais. Têm a finalidade de 
manter o funcionamento adequado do organismo, ou seja, a vida. Os nutrientes são encontrados nas carnes e vegetais e são transformados e distribuídos de modo útil ao organismo humano (RECINE; RADAELLI, 2009).

A cultura, assim como as crenças, tabus, religiões influenciam de forma direta na escolha dos alimentos. A alimentação está relacionada à história de diferentes povos. Para diferenciar e entender as origens dos hábitos alimentares é necessário recordar o passado, costumes, colonização, efeitos da escravidão e a evolução da sociedade até chegar ao período atual (RECINE; RADAELLI, 2009).

O direito a alimentação de qualidade e quantidade satisfatórias é reservado a todo cidadão pela Declaração Universal dos Direitos Humanos (CARVALHO et al., 2003).

As necessidades nutricionais da maior parte dos indivíduos e grupos de pessoas de uma população sadia são atendidas diariamente pela Ingestão Diária Recomendada (IDR), ou seja, a quantidade de vitaminas, minerais e proteínas que deve ser consumida diariamente para suprir as necessidades nutricionais humanas (BRASIL, 1998 ${ }^{\mathrm{b}}$ ).

\subsection{Alimentação Saudável}

Cada alimento desempenha uma determinada função no organismo e isso está relacionado à maior quantidade de nutriente do alimento, podendo ser de proteína, lipídeo, carboidrato, fibra, vitamina ou mineral. Os alimentos são dividos em três grupos, alimentos construtores, reguladores, energéticos e energéticos extras. Os alimentos construtores fornecem proteínas para o corpo e tem a função construtora, pois formam novos tecidos, promove o crescimento e contribui para a 
resistência do organismo as doenças. Possuem substâncias que formam e mantêm os músculos, ossos, sangue, órgãos, a pele e o cérebro. São encontrados em carne, peixe, frango, leguminosas, leite e derivados. Os alimentos reguladores desempenham as funções específicas e vitais nas células e nos tecidos (auxiliam na imunidade do organismo e aumenta a mobilidade no trato gastrointestinal). Os mesmos são ricos em vitaminas, sais minerais e fibras, são encontrados em legumes, frutas e hortaliças. $70 \%$ do peso corporal total correspondem à água, a mesma possui duas funções, sendo, construtora e reguladora (CASTELL, 2004).

Alimentos energéticos fornecem carboidratos e lipídeos ao corpo e possuem a função de fornecer energia para o organismo funcionar. São encontrados nos cereais, tubérculos, raízes e óleos. E os energéticos extras são considerados como caloria vazia, pois são pobres em relação ao valor nutricional (CASTELL, 2004).

Alimentação saudável pode adquirir muitos significados dependendo do país ou região de um mesmo país, cultura e época; seus atributos são: acessibilidade física e financeira, sabor, variedade, cor, harmonia e segurança sanitária. Deve ser entendida como direito humano, compreendendo uma alimentação apropriada às necessidades dos indivíduos em diferentes fases da vida. Seu principal alicerce são os alimentos naturais e produzidos regionalmente, valorizando a cultura alimentar local e facilitando para a população o acesso físico e financeiro. (PINHEIRO; GENTIL, 2005).

A promoção da alimentação saudável é considerada um eixo prioritário de ação para promoção da saúde. O homem tem a necessidade de ter uma alimentação saudável, que seja rica em nutrientes e com a função de suprir as necessidades nutricionais humanas. Isso pode ser adquirido pela utilização de partes dos alimentos que muitas vezes são desprezadas, como cascas, talos, 
sementes e folhas (GONDIM et al., 2005).

Uma boa refeição depende de sua composição nutricional, isso significa que uma alimentação adequada deve ser variada quanto à quantidade, qualidade e variedade dos alimentos a serem ingeridos (PINHEIRO; GENTIL, 2005). Levando em consideração que os alimentos separadamente, na sua grande maioria, são incompletos para atender as necessidades humanas, é necessário variar e complementá-los, pela utilização de partes que normalmente são desprezadas, aumentando assim o valor nutricional da preparação (GALEAZZI, et al., 1999).

As leguminosas, as hortaliças e as frutas são alimentos saudáveis, pois são ricas em fibras alimentares, minerais e vitaminas que protegem contra doenças e auxiliam na imunidade do organismo; no entanto, é fundamental o consumo freqüente desses alimentos (CASTELL, 2004).

As frutas e hortaliças são as principais fontes de nutrientes essenciais. Os minerais são fundamentais, pois eles desempenham uma função vital no desenvolvimento e na manutenção do organismo humano. As frutas são consideradas as principais fontes de minerais necessários na dieta humana (GONDIM et al., 2005).

Alimentar-se adequadamente, nos dias atuais, tem se tornado cada vez mais complexo, uma vez que as dificuldades em adquirir alimentos adequados e de qualidade se tornam maiores devido às situações críticas financeiras vividas por grande parte da população atual (GONDIM et al., 2005).

As condições básicas, assim como habitação, saneamento, saúde e educação têm a função de combater a fome e aumentar os direitos das pessoas de baixa renda, aumentando assim o acesso à alimentação equilibrada proporcionando uma vida saudável (BRASIL, 1990). Entretanto, para se conseguir suprir esses 
pontos é preciso pensar em políticas de desenvolvimentos econômicos capazes de gerar de forma acelerada boas oportunidades de empregos para beneficiar exclusivamente essa determinada classe social (HOFFMANN, 1994).

Melhorar o estado nutricional de uma população não é uma preocupação apenas dos países de terceiro mundo; essa atenção também é dada para as classes menos privilegiadas dos países desenvolvidos. A criação de programas de intervenção alimentar ou nutricional são baseadas em princípios econômicos, políticos e sociais. A mesma tem como objetivo melhorar o estado nutricional das camadas menos desenvolvidas (FARFAN, 1998).

A escassez alimentar, aliada ao baixo poder aquisitivo de parte da população brasileira, é demonstrada por de indicadores antropométricos de desnutrição. O crescimento e a manutenção das dimensões corporais exigem a presença de condições ótimas, especialmente quando se trata de ingestão e utilização biológica de calorias e proteínas. Desse modo, os indicadores antropométricos estabelecem uma maneira sensível de detectar casos de desnutrição (HOFFMANN, 1994).

A desnutrição é uma das principais carências nutricionais no Brasil, sendo que a classe da população de baixa renda se destaca com a maior prevalência devido às dificuldades econômicas de obter alimentos de qualidade e em quantidade suficiente para atender as necessidades humanas. Para solucionar esse problema 0 Instituto Nacional de Alimentação e Nutrição (INAN), em 1992, adotou a utilização do aproveitamento integral dos alimentos como uma alternativa alimentar na recuperação e manutenção dos pacientes. Por meio dessa alternativa foi possível observar que houve melhoras no estado nutricional daquelas pessoas (VIZEU et al., 2005). 
A migração do homem do campo para a cidade ocasionou em profundas transformações na sociedade brasileira, sobretudo, no que diz respeito aos hábitos alimentares. A alimentação tradicional, rica em nutrientes, por muitas vezes presentes em alimentos de baixo custo, vem se perdendo com o passar do tempo, reduzindo assim a quantidade de fibras, proteínas, minerais e vitaminas gradualmente da dieta da população brasileira. Para resgatar os bons hábitos alimentares, que privilegiam o aproveitamento das partes não convencionais dos alimentos (cascas, folhas, semente e talos) e para contribuir com a diminuição do desperdício, o aproveitamento integral dos alimentos é uma ferramenta essencial para combater as transformações dos hábitos alimentares e de suma importância para a sociedade. Por meio dela é possível aproveitar e explorar tudo o que um alimento pode fornecer como fonte de nutrientes ao organismo humano (FURTUNATO, 2007).

\subsection{Aproveitamento Integral dos Alimentos}

O aproveitamento integral dos alimentos é uma alternativa iniciada em 1963 no estado de São Paulo e atualmente continua crescendo. Tem a finalidade de aproveitar as partes que normalmente são desprezadas (OLIVEIRA et al., 2002).

Com o aproveitamento integral dos alimentos é possível reduzir o custo das preparações, contribuir para a diminuição do desperdício alimentar, aumentar o valor nutricional e tornar possível a elaboração de novas preparações (GONDIM et al., 2005).

Aproveitar o máximo e variar a refeição em relação aos alimentos, levando em consideração a sua quantidade adequada são fatores de extrema importância, 
pois por esse meio é possível alcançar o equilíbrio de nutrientes (GALEAZZI et al., 1999).

Com o crescimento populacional e os avanços tecnológicos, o contato com os alimentos a cada dia se torna escasso e possibilita o aumento no índice de desperdício alimentar. Para resolver essa situação é necessário aproveitar ao máximo os alimentos (BANCO DE ALIMENTOS, 2003º).

Pesquisa sobre o consumo consciente dos brasileiros realizada pelo Instituto Akatu envolvendo mais de 1200 pessoas revela que mais da metade dos participantes não fazem uso do aproveitamento dos alimentos (MATTAR, 2008).

A falta de informação sobre aproveitar ao máximo o alimento ocasiona o desperdício de toneladas de recursos alimentares. O desperdício pode ser controlado pelo planejamento de compra e de preparação dos alimentos. $\mathrm{O}$ aproveitamento integral deve ser realizado todos os dias e independentemente de classe social ou econômica (BADAWI, 2008).

$\mathrm{Na}$ produção mundial, são perdidos $30 \%$ dos alimentos, devido às deficiências no sistema de colheita, transporte, armazenagem e comercialização. $O$ lixo do Brasil é considerado o mais rico do mundo, devido ao alto índice de alimentos desperdiçados diariamente; por isso, é considerado o país do desperdício. O desperdício no consumo doméstico de alimentos chega a $20 \%$, devido sua utilização inadequada contribui para o desperdício. Partes dos alimentos como talos, folhas, sementes e cascas são consideradas as partes mais nutritivas em relação às partes normalmente consumidas (IBGE, 2005).

Para combater a fome, o desperdício e a desnutrição que atingem grandes partes populacionais das áreas menos desenvolvidas, são criadas alternativas alimentares, sendo elas de baixo custo (SOUZA et al., 2006). 


\subsection{Programas que Incentivam o Aproveitamento de Alimentos}

O Programa Mesa Brasil do Serviço Social do Comércio (SESC) é um programa de segurança alimentar e nutricional sustentável, voltado para a inclusão social e com o objetivo de combater a fome e o desperdício pela utilização integral dos alimentos. Esse programa busca onde sobra e entrega onde falta, arrecadando e distribuindo alimentos excedentes que são apropriados para o consumo ou sem valor para a comercialização e promovendo oficinas de alimentação saudável gerando, assim, melhorias na qualidade de vida da população de baixa renda. $\mathrm{O}$ programa tem o apoio de empresas, voluntários e instituições sociais (BANCO DE ALIMENTOS, $2003^{\mathrm{b}}$ ).

O programa Fome Zero foi criado em 2003 pelo governo federal com a finalidade de assegurar o direito humano à alimentação adequada às pessoas com dificuldades de acesso aos alimentos, combatendo assim a fome e suas causas estruturais. Esse programa se encaixa na promoção da segurança alimentar e nutricional com o objetivo de inclusão social e a conquista da cidadania da população mais vulnerável à fome. As iniciativas envolvem vários ministérios, as três esferas de governo (federal, estadual e municipal) e a sociedade civil organizada (FOME ZERO, 2009).

O Banco de Alimentos é uma iniciativa de abastecimento e segurança alimentar do Ministério do Desenvolvimento Social e Combate à Fome junto aos municípios que possuem mais de cem mil habitantes. O seu objetivo é arrecadar e distribuir alimentos próprios para o consumo e sem valor comercial, por meio de doações de setores alimentícios (supermercados, indústrias, varejões, feiras e centrais de abastecimento). Os produtos são recebidos, selecionados, separados 
em porções, processados se necessário, embalados e distribuídos gratuitamente às entidades assistenciais, servindo como complementação para as refeições diárias. As entidades sociais atendidas pelos bancos de alimentos participam de atividades de educação alimentar, para repassar o conhecimento à comunidade (MINISTÉRIO DO DESENVOLVIMENTO SOCIAL E COMBATE À FOME, 2009).

A agricultura urbana é responsável em arrecadar e encaminhar para entidades sociais alimentos frescos, produtos hortifrutigranjeiros e alimentos industrializados todos os dias e de forma adequada, garantindo a segurança dos alimentos (MESA BRASIL, 2009).

O Programa de Aquisição de Alimentos (PAA) é uma das iniciativas do programa Fome Zero e seu objetivo é assegurar o acesso aos alimentos em quantidades e qualidades necessárias às populações em condição de insegurança alimentar e nutricional e promover a inclusão social no campo por meio do fortalecimento da agricultura familiar. Os alimentos adquiridos são encaminhados às pessoas em situação de insegurança alimentar e nutricional, atendidas por programas sociais locais e pessoas em situação de risco nutricional (PROGRAMA DE AQUISIÇÃO DE ALIMENTOS, 2009).

Restaurantes Populares são Unidades de Alimentação e Nutrição (UAN) que têm o objetivo de produzir e comercializar refeições saudáveis, diversificadas, econômicas, balanceadas, com alto valor nutricional, oferecidas com os preços acessíveis à população e geralmente localizados preferencialmente nos centros urbanos de cidades com mais de cem mil habitantes. As refeições são produzidas utilizando o aproveitamento integral dos alimentos. O público que frequenta os restaurantes são trabalhadores de baixa renda, sendo eles formais e informais, pessoas desempregados, estudantes, aposentados, moradores de rua, população 
que se encontra vulnerável sócio-economicamente e famílias em situação de risco de insegurança alimentar e nutricional (RESTAURANTE POPULAR, 2009).

O Serviço Social da Indústria (SESI) desenvolve, desde 1999, o programa Alimente-se Bem para auxiliar as pessoas a minimizar o desperdício dos alimentos, por meio da utilização de partes que normalmente não são utilizadas, garantindo assim o aumento da qualidade e o acesso das preparações (MATTAR, 2008).

Esses programas são estratégias de combate a fome e redução do desperdício de alimentos. Dessa forma, são importantes para o avanço do setor e na conscientização da população da redução do desperdício.

\subsection{A Importância das Partes não Convencionais dos Alimentos}

Pesquisa realizada pelo Instituto Akatu revela que o consumidor aproveita apenas $40 \%$ das frutas e hortaliças, devido à falta de orientação sobre a utilização dos talos, folhas, cascas e sementes (MATTAR, 2008).

As cascas das frutas desperdiçadas pela maioria da população apresentam, segundo análises químicas, de um modo geral, uma quantidade de nutrientes maior em relação às próprias partes comestíveis das frutas. As cascas das frutas podem contribuir com a diminuição do desperdício de alimentos e como fonte alternativa de nutrientes (GONDIM et al., 2005).

As cascas das hortaliças são fontes de fibras, vitaminas e sais minerais, que atuam nos organismos humanos como antioxidantes (fatores que evitam o envelhecimento da pele); além disso, regularizam o intestino, previnem a anemia e auxiliam no processo de cicatrização (CASTELL, 2004). 
As cascas estão diretamente expostas a agrotóxicos e outros agentes nocivos. Isso resulta em desvantagem do aproveitamento integral dos alimentos, pois são substancias que prejudica a saúde humana se for ingerida constantemente e ao mesmo tempo são importantes no período de plantio porque protege os alimentos contra pragas. Para reduzir o consumo desses contaminantes é necessário higienizar adequadamente os alimentos antes do consumo (STOPPELLI; MAGALHÃES, 2005).

Os dados sobre a composição de alimentos são importantes, pois permitem que a população consiga se alimentar de forma equilibrada e em acordo com a IDR. As composições auxiliam de diversas formas, como na avaliação do estado nutricional, no consumo alimentar de um país ou região, na verificação da adequação nutricional da dieta de indivíduos e/ou das populações, no desenvolvimento de pesquisas sobre as relações entre dieta e doença, em planejamento agropecuário e na indústria de alimentos (TORRES et al., 2000).

O aproveitamento das partes que normalmente são desprezadas, além de tornar a preparação de baixo custo, ser de fácil acesso e melhorar o valor nutricional, proporciona também o aumento no rendimento da refeição. Com a redução das perdas dos alimentos é possível aumentar a sua disponibilidade (GAVA, 1984).

O impacto ambiental é ocasionado por alterações de propriedades físicas, químicas e biológicas no meio ambiente e podem ser causadas por diversas formas de matéria ou energia resultante das atividades humanas. O aproveitamento integral dos alimentos é uma forma de reduzir o desperdício alimentar e o impacto no meio ambiente, porém, devido à falta de cuidado e de informação, toneladas de alimentos são descartadas no mundo. O desperdício de alimentos está relacionado 
diretamente com o meio ambiente, pois, ao serem jogados fora de forma inadequada no solo, provoca no meio ambiente consequências irreversíveis, como, o odor gerado pela putrefação e o chorume que normalmente encontra-se contaminado e que contamina, por sua vez, os rios e lençóis freáticos. Para obter um meio ecologicamente equilibrado é preciso reduzir o desperdício de alimentos, pois dessa forma reduz os impactos ambientais (SANTOS, 2008). 


\section{METODOLOGIA}

\subsection{DELINEAMENTO DA PESQUISA}

Trata-se de um estudo exploratório quantitativo que busca avaliar a aceitabilidade de preparações com aproveitamento integral dos alimentos.

\subsection{POPULAÇÃO DA AMOSTRA}

Os participantes desta pesquisa foram alunos do período noturno de um curso pré-vestibular localizado em Vitória, Espírito Santo.

Esse pré-vestibular teve início no ano de 2000, com 30 alunos. Seu objetivo é inserir o aluno da rede pública, com renda familiar máxima de três salários mínimos, no ensino superior e pós-médio. Para permanecer no pré-vestibular cada aluno tem que assinar um termo de assiduidade as aulas, onde são avaliados de acordo com as notas e frequência escolar.

Os alunos recebem, gratuitamente, materiais didáticos, uniformes, têm acesso à biblioteca, laboratórios e recursos audiovisuais.

No ano de 2008, o número de matriculados foi de 90 alunos, com faixa etária de 17 a 45 anos, com 45 alunos em cada sala. Todos os alunos do pré-vestibular foram convidados a participar da pesquisa. Nos dias em que ela foi realizada havia 84 alunos presentes na instituição.

Antes de iniciar a pesquisa, foram esclarecidos à diretoria do curso prévestibular os objetivos e os procedimentos do projeto. Após a concordância, os 
diretores assinaram o termo de concordância de participação da instituição (apêndice I).

No primeiro momento, foi explicado aos alunos sobre a ausência de algum tipo de risco decorrente da aplicação dos procedimentos adotados na pesquisa e que a adesão dos participantes era voluntária podendo, a qualquer momento, retirar a sua participação. Todos os alunos aceitaram participar do estudo.

No segundo momento de abordagem, foi explicado aos participantes o objetivo do projeto (apêndice II) e colhida a assinatura do termo de consentimento livre esclarecido (apêndice III), que consistiu nos principais instrumentos para autorização da participação dos escolares selecionados no estudo. Os critérios de exclusão foram ter alergia e/ou não gostar de algum ingrediente das preparações.

\subsection{DESENVOLVIMENTO DAS RECEITAS}

Foram desenvolvidas no Laboratório de Dietética quatro preparações: bolo de banana, bolo de casca de banana, suco de acerola e o suco de acerola, cenoura e couve. As fichas técnicas foram desenvolvidas (apêndices IV a VII) para que pudessem ser padronizadas. No bolo de banana utilizou-se a banana sem a casca e no bolo de casca de banana utilizou-se integralmente a banana (inclusive a casca). No suco de acerola utilizou-se somente a acerola e no suco de acerola, cenoura e couve utilizou-se integralmente a acerola, a cenoura e a couve, inclusive as partes habitualmente não aproveitadas (cascas, sementes, talos e folhas). Sendo essas preparações de alto valor nutricional e de baixo custo, optou-se por um grupo de provadores de baixa renda. 
Para a determinação do valor nutricional das receitas desenvolvidas, utilizouse a tabela Taco (2 $2^{\mathfrak{a}}$ edição, $2^{\underline{a}}$ versão, 2006) e caso algum ingrediente não fosse encontrado, utilizou-se a Tabela de Composição de Alimentos: Suporte para Decisão Nutricional (Philippi, 2002). Foram calculados o valor energético total, os macronutrientes e o teor de fibras (apêndice IV a VII).

\subsection{VERIFICAÇÃO DA ACEITABILIDADE}

Foi elaborado um questionário de aceitabilidade (apêndice VIII) com as seguintes variáveis: faixa etária, sexo, renda, local de residência, ocupação, questões relacionadas às práticas e hábitos de cozinhar em casa, custo das receitas e escalas de aceitação do bolo e do suco, no total de 17 perguntas, sendo que 12 abertas e 5 fechadas.

A aplicação do questionário de aceitabilidade foi feita em dois dias, sendo que no primeiro dia foi com as preparações utilizando o aproveitamento integral dos alimentos e no outro dia com as preparações sem o uso do aproveitamento integral dos alimentos. A análise de aceitabilidade foi realizada com duas escalas hedônicas (bolo e suco) de 5 pontos (no qual o ponto número 1 significava desgostei muito, número 2 desgostei moderadamente, número 3 indiferente, número 4 gostei moderadamente e número 5 gostei muito).

Antes de iniciar a aplicação do questionário, os participantes foram orientados como deveriam preenchê-los de forma adequada; após essa orientação foi solicitado 20 minutos de silêncio para que não houvesse comunicação entre eles, que estavam em carteiras distanciadas uns dos outros. Em cada mesa havia uma bandeja com duas preparações (sobre as quais os alunos não foram informados os 
tipos), um copo de água e um questionário.

Após essa etapa, os questionários foram recolhidos e para cada participante foram entregues informativos sobre as preparações oferecidas, sendo elas, bolo de banana, bolo de casca de banana, suco de acerola e suco de acerola, cenoura e couve, conforme consta nos apêndices IX a XII respectivamente.

\subsection{PLANO DE ANÁLISE DE DADOS}

As respostas dos alunos foram analisadas por meio de um questionário de aceitação. Para a realização das análises estatísticas, os dados foram armazenados e analisados em planilhas. As notas referentes às escalas hedônicas foram analisadas pelo teste $\mathrm{T}$ de student, onde foi utilizado o nível de significância de 5\%. Para a tabulação e análises gráficas, foram utilizadas as planilhas e os gráficos do programa Microsoft Excel (versão 97). 


\section{RESULTADO E DISCUSSÃO}

Dos 90 alunos convidados para participar desta pesquisa como provadores, $93,3 \%$ aderiram ao estudo.

A Tabela 1 apresenta características dos alunos participantes da pesquisa conforme questionário de aceitabilidade empregado. Observa-se que a maioria dos alunos envolvidos no estudo é de jovens menores de 25 anos. O sexo feminino foi predominante com $60,7 \%$ do total dos participantes. A baixa renda é uma das principais características dos alunos daquele curso pré-vestibular; aproximadamente, $72,6 \%$ do total da amostra vivem com renda familiar de até 3 salários mínimo e 39,3\% dos participantes habitam em Vitória.

No Brasil, segundo os dados do IBGE de 2007, aproximadamente $50,7 \%$ da população total é do sexo feminino. Conforme o censo realizado em Vitória, no Espírito Santo, o número total de habitantes é de 282.606,00 (duzentos e oitenta e dois milhões e seiscentos e seis mil) sendo que $52,8 \%$ dos mesmos são do sexo feminino; portanto, isso justifica a predominância do sexo feminino na pesquisa realizada. Comparando a proporção dos jovens com a idade inferior e superior a 25 anos, a prevalência é maior nos que possuem a idade inferior a 25 anos. No censo realizado em 2007, 70,1\% da população possuem a renda familiar mensal de no máximo 3 salários mínimos, isso explica o alto percentual observado na pesquisa realizada. Como previamente esperado, devido à localização do pré-vestibular, grande parte dos alunos residem em Vitória (IBGE, 2009). 
Tabela 1. Características sócio-demográficas dos alunos participantes. Vitória 2008.

\begin{tabular}{|c|c|c|}
\hline Variáveis & $\mathbf{N}$ & $\%$ \\
\hline \multicolumn{3}{|l|}{ Faixa Etária } \\
\hline 16 a 24 anos & 65 & 77,4 \\
\hline 25 a 48 anos & 19 & 22,6 \\
\hline Total & 84 & 100 \\
\hline \multicolumn{3}{|l|}{ Sexo } \\
\hline Feminino & 51 & 60,7 \\
\hline Masculino & 33 & 39,3 \\
\hline Total & 84 & 100 \\
\hline \multicolumn{3}{|l|}{ Renda } \\
\hline$\leq 1 * \mathrm{SM}$ & 8 & 9,5 \\
\hline$>1{ }^{*} \mathrm{SM}$ a $2{ }^{*} \mathrm{SM}$ & 27 & 32,1 \\
\hline$>2$ *SM a 3 *SM & 26 & 31,0 \\
\hline$>3{ }^{*} \mathrm{SM}$ & 23 & 27,4 \\
\hline Total & 84 & 100 \\
\hline \multicolumn{3}{|l|}{ Município } \\
\hline Vitória & 33 & 39,3 \\
\hline Cariacica & 28 & 33,3 \\
\hline Vila Velha & 13 & 15,5 \\
\hline Outros & 10 & 11,9 \\
\hline Total & 84 & 100 \\
\hline
\end{tabular}

*SM significa Salário Mínimo.

De acordo com a Tabela 2 pode-se observar que a maior parte dos participantes $(60,7 \%)$ é de estudantes e trabalhadores e que $53,6 \%$ dos entrevistados não possuem hábito de cozinhar em casa. As mães foram citadas com 60,7\% como responsáveis pela preparação das refeições em casa. A maioria dos alunos entrevistados $(67,9 \%)$ informou que já tinham ouvido falar do aproveitamento integral dos alimentos, e ressaltou que o seu significado é aproveitar o alimento na sua totalidade. $57,1 \%$ dos participantes responderam que é uma forma de evitar o desperdício, pois aproveita o máximo dos alimentos.

Conforme os dados do IBGE de 2007 , a população brasileira possui $67,8 \%$ de pessoas maiores de 15 anos que estudam e trabalham. Em Vitória, no Espírito 
Santo, os dados encontrados foram de $61 \%$ para os maiores de 15 anos que estudam e trabalham; no entanto, por esse dado é possível afirmar que eles não possuem hábitos de preparar as refeições em casa devido à rotina diária, que no caso é estudar e trabalhar. Em relação aos afazeres domésticos, $91 \%$ das mães foram citadas; sendo assim, elas são responsáveis por preparar as refeições (VITÓRIA, 2009). Pesquisa realizada pelo Instituto Akatu com mais de 1200 pessoas revela que $60 \%$ dos participantes já ouviram falar em aproveitamento integral dos alimentos, porém $8,3 \%$ disseram que aproveitam os talos, sementes, cascas e folhas dos alimentos (MATTAR, 2008). No Brasil, são produzidos 43,8 milhões de toneladas de detritos por ano. Cada brasileiro gera em torno de um quilo de lixo por dia. Cerca de $65 \%$ desse total é representado por lixo orgânico, formado de restos de alimentos; $25 \%$ é composto de papel; $4 \%$ de metal; $3 \%$ de vidro e $3 \%$ de plástico (MATTAR, 2008). Aproveitar os alimentos na sua totalidade é utilizar as partes que normalmente são descartadas; com isso é possível aumentar o valor calórico da preparação, reduzir o desperdício e o custo. 
Tabela 2. Caracterização do Perfil dos Degustadores. Vitória 2008.

\begin{tabular}{lrc}
\hline Variáveis & N & $\%$ \\
\hline Ocupação & & \\
Só Estuda & 19 & 22,6 \\
Estuda e Trabalha & 51 & 60,7 \\
Estuda somente no projeto & 14 & 16,7 \\
Total & 84 & 100 \\
Cozinha em casa? & & \\
Não & 45 & 53,6 \\
Sim & 39 & 46,4 \\
Total & 84 & 100 \\
Quem Cozinha? & \\
Mãe & 51 & 60,7 \\
Próprio & 21 & 25,0 \\
Outros & 12 & 14,3 \\
Total & 84 & 100 \\
Já ouviu falar e Aproveitamento Integral dos Alimentos? & \\
Não & 27 & 32,1 \\
Sim & 57 & 67,9 \\
Total & 84 & 100 \\
O que entende sobre Aproveitamento Integral dos Alimentos? & \\
Evita Desperdício & 48 & 57,1 \\
Nutritivo & 7 & 34,5 \\
Não sabe & 29 & 8,4 \\
Total & 84 & 100 \\
\hline
\end{tabular}

A Figura 1 mostra a escala de aceitação das preparações modificada e padrão. Observa-se que a aceitação do bolo de casca de banana, preparação modificada, foi maior em relação ao bolo de banana, preparação padrão. 


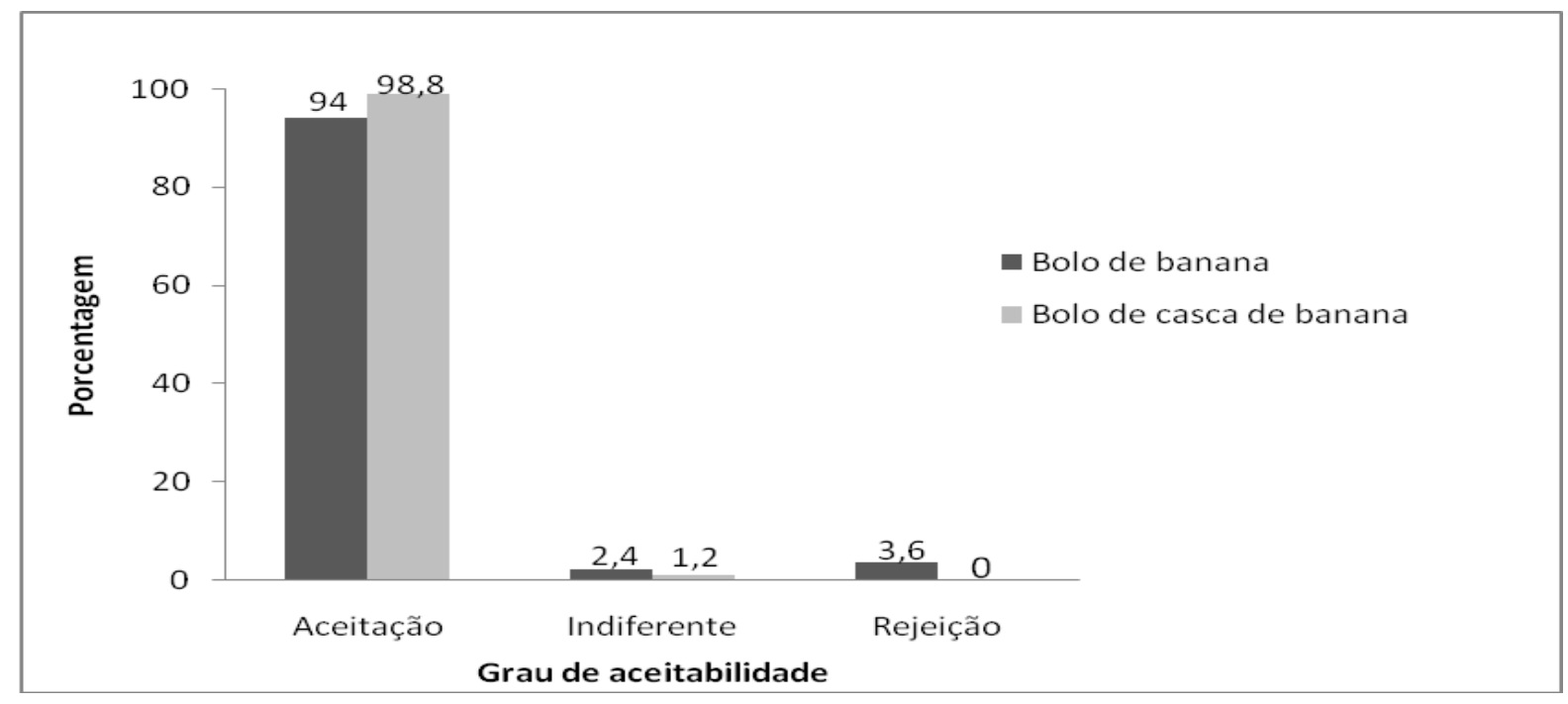

Figura 1. Percentual de aceitação do bolo de banana e do bolo de casca de banana. Vitória 2008.

$\mathrm{Na}$ Figura 2, pode-se observar que a escala de aceitação das preparações modificada e padrão de suco. Nota-se que o suco de acerola, preparação padrão, foi mais aceito em relação ao suco de acerola, cenoura e couve, preparação modificada.

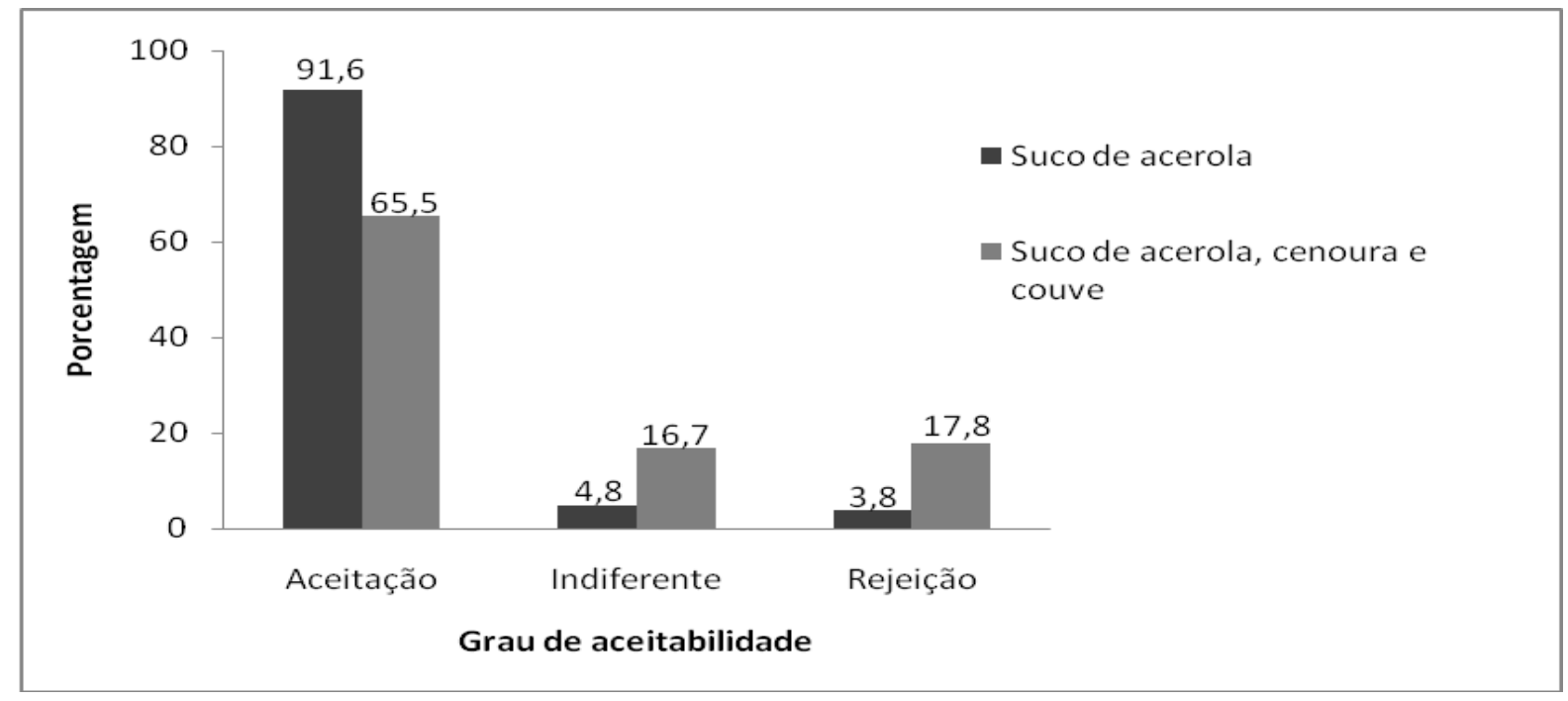

Figura 2. Percentual de aceitação do suco de acerola e o suco de acerola, cenoura e couve. Vitória 2008. 
Pelas médias obtidas e pelo teste $\mathrm{T}$, o bolo de banana e o bolo de casca de banana, respectivamente, apresentaram notas médias de 4,73 e 4,36, sendo o $p=$ 0,08 . Isso significa que para os provadores não há diferença entre os bolos e as notas médias estão na faixa de aceitação do produto. A média referente ao suco de acerola foi de 4,56 e para o suco de acerola, cenoura e couve foi de 3,77 , sendo o $p=0,0001$. Desta forma, o uso integral dos alimentos para fazer o suco não obteve a mesma aceitabilidade do suco puro de acerola, apesar de ter nota média na faixa de aceitação. $17,8 \%$ dos provadores rejeitaram o suco de acerola, cenoura e couve, indicando que mudanças simples como diminuir a quantidade de couve e aumentar a quantidade de açúcar poderia melhorar a aceitabilidade desse produto.

A partir dos resultados apresentados na Tabela 3, verifica-se que no bolo padrão, $89,3 \%$ dos provadores identificaram a banana como sendo o ingrediente principal da receita, 5,9\% identificaram banana, laranja, cenoura e goiaba e 3,6\% identificaram a banana com a casca de banana, sendo que o bolo padrão foi um bolo de banana e o principal ingrediente foi somente a banana sem casca. No bolo modificado foi identificado por $66,7 \%$ dos participantes que a preparação era de banana, $19 \%$ identificaram banana com o chocolate, 9,5\% a banana com a casca e $4,8 \%$ a banana com canela, laranja, abacaxi e beterraba. O bolo modificado foi de casca de banana e seu principal ingrediente era a banana com a casca.

No suco padrão, $59,5 \%$ dos provadores identificaram a acerola como o ingrediente principal, 23,8\% identificaram acerola, goiaba, limão, cenoura laranja, couve e o mamão e $13,1 \%$ identificaram o cajá, pitanga e a goiaba. O suco padrão foi de acerola e o principal ingrediente era a acerola. No suco modificado foi identificada a acerola para $53,6 \%$ dos participantes, $27,4 \%$ identificaram a pitanga, tamarindo, goiaba, cajá, laranja e carambola e 13,1\% identificaram a acerola, 
cenoura e a couve. O suco modificado foi de acerola, cenoura e couve e esses foram os ingredientes principais da receita.

Tabela 3. Identificação dos provadores em relação aos ingredientes das preparações. Vitória 2008.

\begin{tabular}{lcc} 
Variáveis & N & $\%$ \\
\hline Bolo de Banana & & \\
Banana & 35 & 89,3 \\
Banana com casca & 5 & 3,6 \\
Banana, laranja, cenoura, goiaba & 1 & 1,9 \\
Não Sabe & 84 & 100 \\
Total & & \\
Bolo de Casca de Banana & 56 & 66,7 \\
Banana & 8 & 9,5 \\
Banana com casca & 16 & 19,0 \\
Banana com chocolate & 4 & 4,8 \\
Banana, canela, laranja, abacaxi, beterraba & 84 & 100 \\
Total & & \\
Suco de Acerola & 50 & 59,5 \\
Acerola & 20 & 23,8 \\
Acerola, goiaba, limão, cenoura, couve, laranja, mamão & 11 & 13,1 \\
Cajá, pitanga e goiaba & 3 & 3,6 \\
Não Sabe & 84 & 100 \\
Total & & \\
Suco de Acerola, Cenoura e Couve & 45 & 53,6 \\
Acerola & 11 & 13,1 \\
Acerola, cenoura, couve & 23 & 27,4 \\
Pitanga, tamarindo, goiaba, cajá, laranja, carambola & 5 & 5,9 \\
Não Sabe & 84 & 100 \\
Total & \multicolumn{2}{c}{} \\
\hline
\end{tabular}

A Tabela 4 indica a distinção dos provadores referente ao questionário de receitas padrões. O bolo e o suco foram aceitos com $67,8 \%$. Dos provadores, $92 \%$ afirmaram que fariam as receitas em casa. Ao perguntar por que as fariam $83,3 \%$ citaram porque são gostosas e 11,9\% mencionaram porque são nutritivas. A maior parte dos participantes, $85,7 \%$ respondeu que eventualmente utilizaria para substituir um lanche da tarde. 
Tabela 4. Distinção dos provadores referente às receitas - padrão. Vitória 2008.

\begin{tabular}{lcc}
\hline Variáveis & N & $\%$ \\
\hline Qual (s) preparação (s) você gostou & 25 & 29,8 \\
Bolo & 2 & 2,4 \\
Suco & 57 & 67,8 \\
Bolo e Suco & 84 & 100 \\
Total & & \\
Faria essa receita em casa? & 78 & 92 \\
Sim & 6 & 7,1 \\
Não & 84 & 100 \\
Total & & \\
Porquê? & 70 & 83,3 \\
Gostoso & 10 & 11,9 \\
Nutritivo & 4 & 4,8 \\
Não Gostou & 84 & 100 \\
Total & \multicolumn{2}{c}{ (c) } \\
Utilizaria essas preparações para substituir um lanche da tarde? \\
Sim & 72 & 85,7 \\
Não & 12 & 14,3 \\
Total & 84 & 100 \\
\hline
\end{tabular}

$\mathrm{Na}$ Tabela 5 pode-se observar as respostas do questionário da receita modificada. O bolo foi à preparação que obteve a maior aceitabilidade com 52,4\% Dos provadores, $88,1 \%$ afirmaram que fariam as receitas em casa, pois elas são gostosas (50\%), nutritivas $(39,3 \%)$ e eventualmente utilizariam as preparações para substituir um lanche da tarde (85,7\%). 
Tabela 5. Distinção dos provadores referente às receitas modificadas. Vitória 2008.

\begin{tabular}{lcc}
\hline Variáveis & N & $\%$ \\
\hline Qual (s) preparação (s) você gostou & \multicolumn{3}{c}{} \\
Bolo & 2 & 52,4 \\
Suco & 38 & 2,4 \\
Bolo e Suco & 84 & 100 \\
Total & & \\
Faria essa receita em casa? & 74 & 88,1 \\
Sim & 10 & 11,9 \\
Não & 84 & 100 \\
Total & \multicolumn{2}{c}{} \\
Porquê? & 42 & 50 \\
Gostoso & 33 & 39,3 \\
Nutritivo & 9 & 10,7 \\
Não Gostou & 84 & 100 \\
Total & 72 & 85,7 \\
Utilizaria essas preparações para substituir um lanche da tarde? & 72 \\
Sim & 12 & 14,3 \\
Não & 84 & 100 \\
Total & \multicolumn{3}{c}{} \\
\hline
\end{tabular}

Conforme mostra a Figura 3 é possível observar que 42,9\% dos provadores superestimaram o custo da preparação do bolo de banana, pois o valor real da preparação, conforme o informativo contido no apêndice IX foi de $R \$ 3,60$. Em relação ao bolo de casca de banana, $50 \%$ dos provadores subestimaram o custo da preparação, pois o valor real foi segundo o apêndice $X$ de $R \$ 5,20$. 


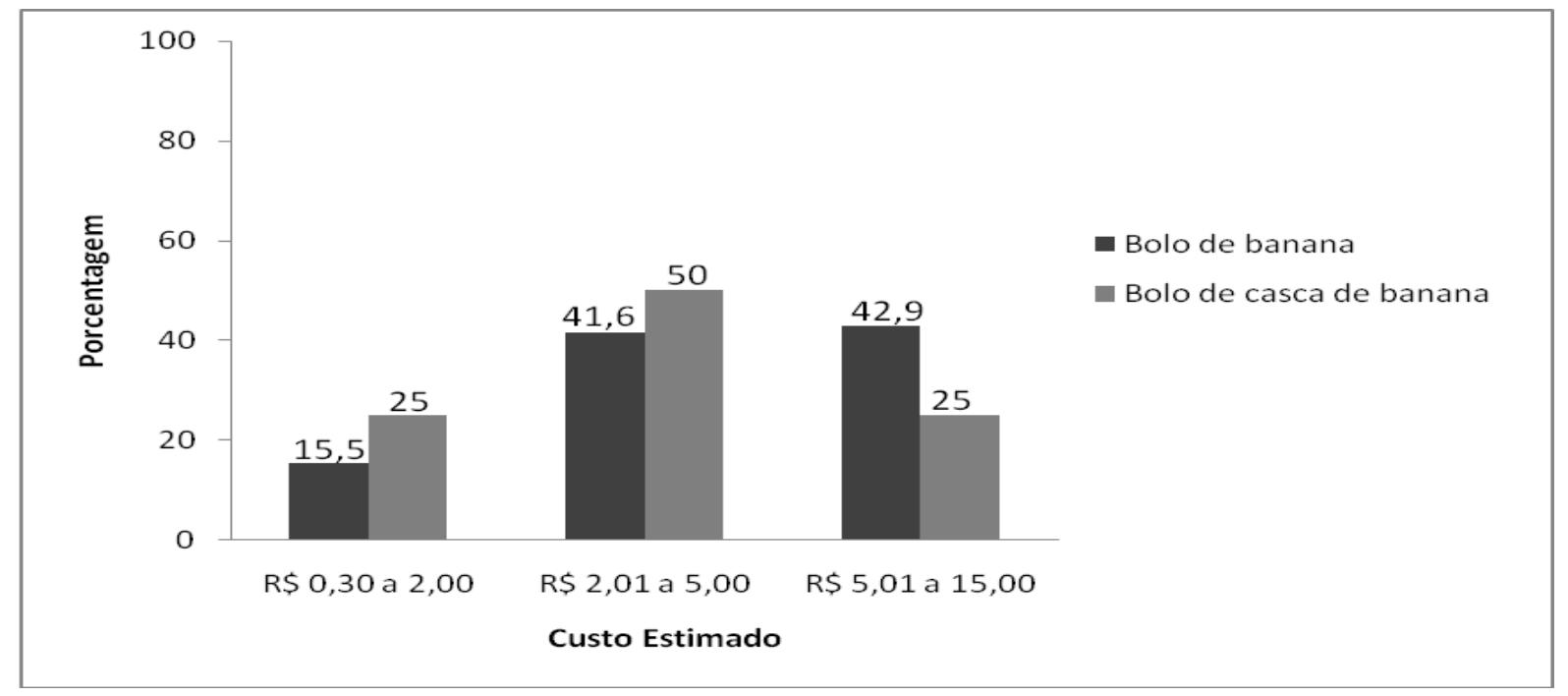

Figura 3. Frequência de provadores (\%) segundo o custo (em reais) do bolo de banana e o bolo de casca de banana, estimado pelos os mesmos. Vitória, 2008.

De acordo com a Figura 4, os provadores estimaram o custo do suco de acerola e do suco de acerola, cenoura e couve entre os valores de $R \$ 2,01$ a 5,00 . $O$ custo real das preparações foi de $R \$ 4,30$ e 5,00, respectivamente, conforme o apêndice XI e XII.

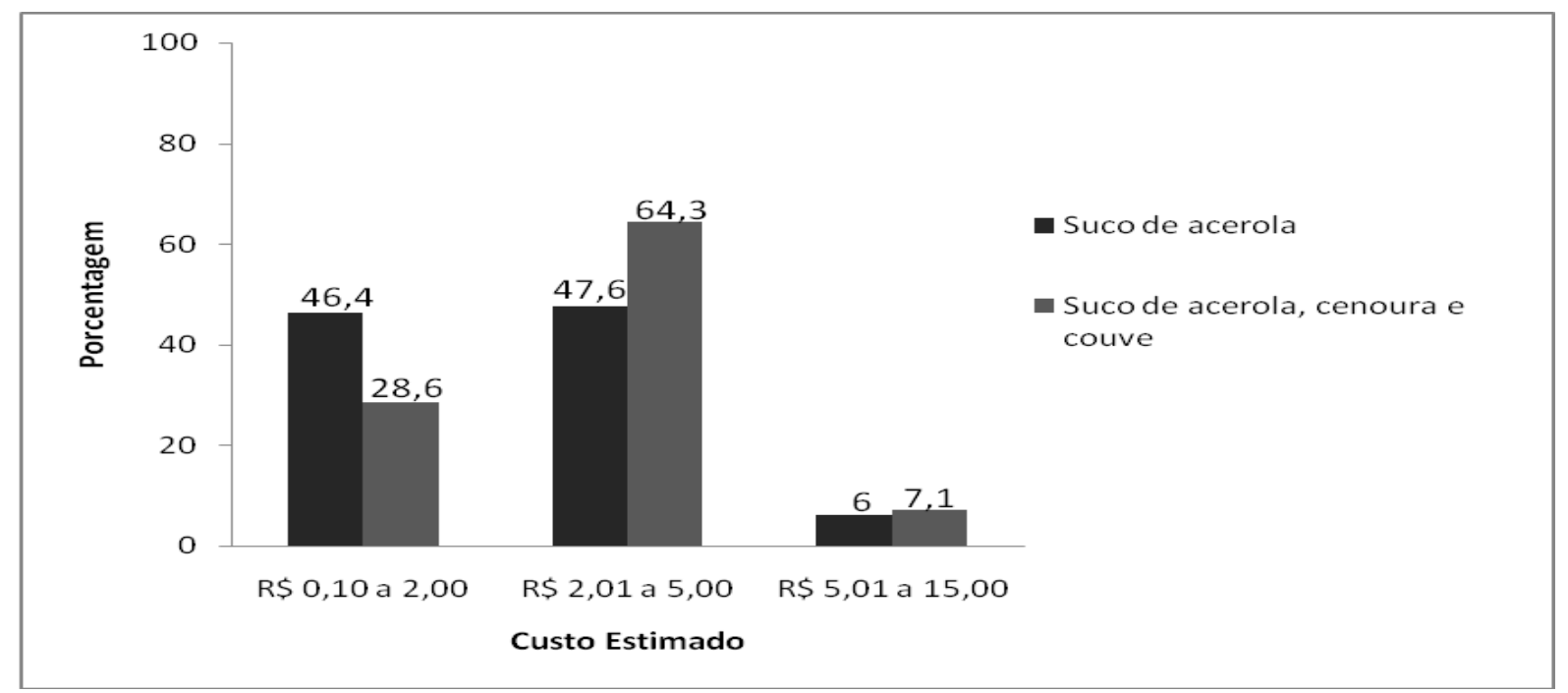

Figura 4. Frequência de provadores (\%) segundo o custo (em reais) do suco de acerola e o suco de acerola, cenoura e couve, estimado pelos os mesmos. Vitória, 2008. 
Dados obtidos segundo as fichas técnicas de preparo (apêndice III) mostram os valores calóricos das preparações e indicam que uma porção de $70 \mathrm{~g}$ do bolo de banana possui 255,33 Kcal, 6,23\% de proteína, 11,88\% de lipídio, $81,89 \%$ de carboidrato e 0,65g de fibra. Em $70 \mathrm{~g}$ do bolo de casca de banana há 246,06 Kcal, 7,02\% de proteína, $12,35 \%$ de lipídio, $80,63 \%$ de carboidrato e 1,35g de fibra.

Em 300 ml de suco de acerola há 162,54 Kcal, 1,48\% de proteína, 1,66\% de lipídio, 96,86\% de carboidratos e $0,70 \mathrm{~g}$ de fibra, sendo que, no suco de acerola, cenoura e couve obteve-se 181,89 Kcal, 2,92\% de proteína, 2,03\% de lipídio, $95,05 \%$ de carboidratos e $1,65 \mathrm{~g}$ de fibra.

Cada uma das preparações em questão pode substituir um lanche escolar devido as calorias mencionadas. As porções das preparações apresentam mais de $10 \mathrm{~g}$ de açúcar, portanto não são indicadas pelo guia da população brasileira. A Organização Mundial de Saúde - OMS recomenda essas preparações, pois elas possuem menos de 30\% de lipídios por porção (VIANA et al., 2007).

Comparando as calorias dos bolos e dos sucos, é possível observar que o bolo de banana, em relação ao bolo de casca de banana, é mais calórico, e o suco de acerola, cenoura e couve possui mais calorias que o suco de acerola. Tanto nos bolos quanto nos sucos, os valores de fibras das receitas modificadas são duas vezes maiores comparando com as receitas padrões. Segundo a portaria no 27 de 1998, as preparações modificadas são classificadas como fonte de fibras, pois possuem a diferença de $25 \%$ do valor de fibra em relação às preparações padrões (BRASIL, 1998 ${ }^{\mathrm{b}}$ ).

Os dados citados sobre a quantidade de fibra das preparações padrões e modificadas são referentes às partes comestíveis; no entanto, não estão 
relacionados aos talos, sementes, folhas e cascas dos ingredientes utilizados na elaboração das receitas.

Estudo envolvendo cascas, talos, folhas e sementes indica que 100 gramas de casca de banana possui $2,35 \mathrm{~g}$ de fibra, $100 \mathrm{~g}$ de folha de couve contem $1,56 \mathrm{~g}$ de fibra e $100 \mathrm{~g}$ de talo de couve tem $1,39 \mathrm{~g}$ de fibra. As partes que foram analisadas (talos, cascas e folhas) são boas fontes de fibras, independentemente do modo de cultivo, podendo ser convencional ou orgânico (ROCHA et al., 2008). 


\section{CONCLUSÃO}

O presente trabalho cumpriu o objetivo da pesquisa verificando a aceitabilidade das preparações padrões e modificadas. Por meio dele é possível afirmar que o aproveitamento integral dos alimentos é a sua utilização na totalidade, pois utiliza os talos, sementes, cascas e folhas. A finalidade é contribuir para a redução da fome devido ao grande número de alimentos que são descartados diariamente, diminuir o gasto com a alimentação, reduzir o custo da preparação, proporcionar o aumento no rendimento e aumentar o valor nutricional das preparações; no entanto, as partes não convencionais são normalmente desprezadas e contêm mais nutrientes em relação às partes convencionais, sendo que ao descartá-las são perdidas vitaminas, minerais, proteínas e fibras.

O estudo revelou que a maioria dos participantes são jovens, estudantes, trabalhadores, do sexo feminino, menores de 25 anos, com renda familiar até 3 salários mínimo, residentes do município de Vitória e não possuem hábito de cozinhar em casa. As mães foram mais mencionadas como responsáveis em preparar as refeições em casa. Grande parte dos participantes assegurou já ter ouvido falar em aproveitamento integral dos alimentos e que o significado é aproveitar os alimentos na sua totalidade evitando assim o desperdício alimentar. Tanto no bolo padrão quanto no bolo modificado o ingrediente principal identificado pela maior parte dos provadores foi à banana, sendo que eram banana e casca de banana, respectivamente. Nos sucos padrão e modificado os provadores identificaram a acerola, sendo que eram a acerola e a acerola, cenoura e a couve respectivamente. 
Ao desenvolver e avaliar a aceitabilidade das preparações padrões e modificadas, é possível observar que elas tiveram bons percentuais de aceitação, porém os bolos foram mais aceitos que os sucos. O bolo de banana foi aceito com $94 \%$, o bolo de casca de banana com $98,8 \%$, o suco de acerola com $91,6 \%$ e o suco de acerola, cenoura e couve com $65,5 \%$. Para melhorar a aceitabilidade do suco modificado é necessário alterar os ingredientes da receita. Uma porção de $70 \mathrm{~g}$ do bolo padrão contém $0,65 \mathrm{~g}$ de fibra e $1,35 \mathrm{~g}$ de fibra no bolo modificado. Um copo de $300 \mathrm{ml}$ do suco padrão possui $0,70 \mathrm{~g}$ de fibra e $1,65 \mathrm{~g}$ de fibra no suco modificado. $\mathrm{O}$ valor da preparação do bolo de banana e do bolo de casca de banana foi calculado em $R \$ 3,60$ e $R \$ 5,20$, respectivamente. O suco padrão e modificado foi calculado em $R \$ 4,30$ e $R \$ 5,00$, respectivamente.

Levando em consideração que o aumento no valor nutricional das preparações é importante para esse estudo, ao comparar as preparações padrão e modificada é possível observar que as modificadas possuem o valor nutricional maior em relação às preparações padrão.

Desenvolver programas de educação ambiental e nutricional com a finalidade de estimular desperdício de alimentos e resgatar a alimentação saudável são medidas a serem tomadas para minimizar o desperdício alimentar. Para alcançar melhorias no equilíbrio social, é fundamental que o consumidor tenha consciência de suas necessidades nutricionais e perceba sua habilidade de transformar a realidade a partir do consumo diário e da capacidade de influenciar os hábitos de consumo da comunidade. Sensibilizar a sociedade em relação à diminuição do lixo orgânico aumenta a concepção de que saúde pessoal se relaciona com a alimentação e meio ambiente, estimulando o interesse de práticas cada vez mais saudável no cotidiano. 
A falta de informação sobre o valor nutritivo dos alimentos, aliada ao desconhecimento de preparo e do aproveitamento máximo são fatores que contribuem para o desperdício. Visto isso, são necessárias pesquisas, trabalhos e tabelas com dados sobre as partes não convencionais, pois, por esse meio é possível calcular o valor nutritivo das preparações e aumentar o conhecimento sobre seu conteúdo nutricional.

O índice de pessoas que faz o uso do aproveitamento integral dos alimentos é pequeno. Para aumentar o conhecimento populacional é necessário que divulgações sejam feitas com alternativas alimentares, sobre como aproveitar corretamente os alimentos, principalmente nas escolas, creches e comunidades, a fim de que essa proposta seja aceita e faça parte dos hábitos alimentares da população.

A realização desse estudo ressalta a importância de desenvolver trabalhos e pesquisas sobre o valor nutricional das partes que costumam ser desprezadas e que poderiam se aproveitadas para melhorar a qualidade e a diversidade das refeições. 


\section{REFERÊNCIAS}

BADAWI, Camila. Aproveitamento Integral dos Alimentos - Melhor sobrar do que faltar? São Paulo. Disponível em: <http://www.nutrociencia.com.br> Acesso em: 27 out. 2008.

BANCO DE ALIMENTOS. Banco de Alimentos e Colheita Urbana: aproveitamento integral dos alimentos. Rio de Janeiro, SESC/DN, 2003 ${ }^{\text {a. }}$

BANCO DE ALIMENTOS. Banco de Alimentos e Colheita Urbana: noções básicas sobre alimentação e nutrição. Rio de Janeiro, SESC/DN, $2003^{\mathrm{b}}$.

BRASIL. Lei no 8.080 , de 19 de setembro de 1990. Dispõe sobre as condições para a promoção, proteção e recuperação da saúde, a organização e o funcionamento dos serviços correspondentes e dá outras providências. Brasília, 19 de setembro de 1990.

BRASIL. Decreto - Lei no. 986 de 21 de outubro de 1969. Institui normas básicas sobre alimentos. Brasília, 21 de outubro de 1969.

BRASIL. Ministério da Saúde. Secretaria - Executiva. Secretaria de Atenção à Saúde. Glossário Temático: alimentação e nutrição. Ministério da Saúde. Secretaria-Executiva. Secretaria de Atenção à Saúde. Brasília: Editora do Ministério da Saúde, 2008. P. 60.

BRASIL. Portaria ํㅡ 27, de 13 de janeiro de 1998. Aprova o Regulamento Técnico referente à Informação Nutricional Complementar (declarações relacionadas ao conteúdo de nutrientes), constantes do anexo desta Portaria. Diário Oficial da União; Poder Executivo, de 16 de janeiro de $1998^{\mathrm{a}}$.

BRASIL. Portaria no 33, de 13 de janeiro de 1998. Ingestão Diária Recomendada (IDR) para proteínas, vitaminas e minerais. Diário Oficial da República Federativa do Brasil, Brasília, 16 de janeiro de $1998^{\mathrm{b}}$.

CARVALHO, Marcelo Soares; BEZERRA NETO, Pedro dos Santos; MANZANO, Sofia Pádua. Pobreza e Desnutrição no Brasil: Avaliação do programa "incentivo ao combate as carências nutricionais (ICCN)". Caderno de Debates. Campinas, v. 10, p. 25 - 42, set. 2003.

CASOTTI, Leticia et al. Consumo de Alimentos e Nutrição: dificuldades práticas e teóricas. Revista Cadernos de Debate, Campinas, v. 6, p. 26 - 39, 1998.

CASTELL, Gemma Salvador. Larousse da Dieta e da Nutrição. São Paulo: Larousse do Brasil, 2004. P. 9 - 33.

FAO/WHO (Organização das Nações Unidas para Agricultura e Alimentação/Organização Mundial de Saúde), 1991. 
FARFAN, Jaime Amaya. Alimentação Alternativa: análise crítica de uma proposta de intervenção nutricional. Caderno de Saúde Pública. Rio de Janeiro, v.14, n.1, p. 205 - 212, jan./mar. 1998.

FERREIRA, Aurélio Buarque de Holanda. Miniaurélio: o dicionário da língua portuguesa. 6. ed. rev. atual. Curitiba: Positivo, 2005.

FOME ZERO. Disponível em: <http://www.fomezero.gov.br/o-que-e> Acesso em: 02 jan. 2009.

FURTUNATO, Dalva. Maria. Nóbrega. Alimentação alternativa (Multimistura) e seus Principais Componentes. Informativo Profissional do Conselho Federal de Farmácia. Infamar. Brasília, v. 19, n. 5/8, p. $103-110,2007$.

GALEAZZI, Maria Antonia Martins et al. Alimentação Adequada para Elaboração do Sistema "melhores compras". Revista Cadernos de Debate. Campinas, v. 7, p. $65-80,1999$.

GAVA, Altanir Jaime. Princípio de Tecnologia de Alimentos. São Paulo: Nobel, 1984.

GONDIM, Jussara Aparecida Melo et al. Composição Centesimal e de Minerais em Casca de Frutas. Revista de Ciência e Tecnologia de Alimentos. São Paulo, v. 25, n. 4, p. 825 - 827, out./dez. 2005.

HOFFMANN, Rodolfo. A insegurança alimentar no Brasil. Revista Cadernos de Debate. São Paulo, v. 2 , p. $1-11.1994$.

IBGE - INSTITUTO BRASILEIRO DE GEOGRAFIA E ESTATístICA. Disponível em: <http://www.ibge.gov.br/cidadesat/topwindow.htm?1> Acesso em 05 fev. 2009.

IBGE - INSTITUTO BRASILEIRO DE GEOGRAFIA E ESTATÍSTICA. Indicadores Agropecuários 1996 - 2003. Rio de Janeiro, março, 2005.

MALUF, Renato Sergio; MENEZES, Francisco; VALENTE, Flávio Luiz. Contribuição ao Tema da Segurança Alimentar no Brasil. Revista Cadernos de Debate, Campinas, v. 4, p. 66 - 88, 1996.

MATTAR, Helio. Caderno Temático: a nutrição e o consumo consciente. São Paulo, 2007; Disponível em <http://www.akatu.org.br $>$ Acesso em: 10 nov. 2008.

MESA BRASIL. Disponível em: <http://www.mesabrasil.sesc.com.br/oquee.html> Acesso em: 02 jan. 2009.

MINISTÉRIO DO DESENVOLVIMENTO SOCIAL E COMBATE À FOME. Banco de Alimentos. Disponível em: <http://www.mds.gov.br/programas/seguranca-alimentar-e-nutricional-san/banco-dealimentos > Acesso em: 02 jan. 2009.

OLIVEIRA, Lenice Freiman et al. Aproveitamento Alternativo da Casca do Maracujá-Amarelo (Passiflora Edulis F. Flavicarpa) para Produção de Doce em Calda. Revista de Ciência de Tecnologia de Alimento, Campinas, v.22, n. 3, p. 259 -262, set./dez. 2002. 
PINHEIRO, Anelise Rizzolo de Oliveira; GENTIL, Patrícia Chaves. A Iniciativa de Incentivo ao Consumo de Frutas, Verduras e Legumes ( $\mathbf{f}, \mathbf{I}$ \& v): uma estratégia para abordagem intersetorial no contexto da Segurança Alimentar e Nutricional (CONSEA - Brasil), Brasília, 2005.

PROGRAMA DE AQUISIÇÃO DE ALIMENTOS. Disponível em: $<$ http://www.mds.gov.br/programas/seguranca-alimentar-e-nutricional-san/programa-de-aquisicao-dealimentos-paa> Acesso em 02 jan. 2009.

RECINE, Elisabetta; RADAELLI, Patrícia. Alimentação e cultura. Brasília, DF. Disponível em: $<$ http://nutricao.saude.gov.br/documentos/alimentacao cultura.pdf>. Acesso em: 02 jan. 2009.

RESTAURANTE POPULAR. Disponível em: <http://www.mds.gov.br/programas/seguranca-alimentare-nutricional-san/restaurante-popular> Acesso em 02 jan. 2009.

ROCHA, Suraya Abdallah et al. Fibras e Lipídios em Alimentos Vegetais Oriundos do Cultivo Orgânico e Convencional. Revista Simbio - Logias. São Paulo, v. 1, n. 2, nov. 2008.

SANTOS, Lígia Amparo da Silva et al. Uso e Percepções da Alimentação Alternativa no Estado da Bahia: um estudo preliminar. Revista de Nutrição, Campinas, v. 14, p. 35 - 40, 2001.

SANTOS, Maria Helena Oliveira. Desperdício de alimentos e sua interferência no meio ambiente. Instituto Construir e Conhecer. Goiânia, n. 5, 2008.

SESI - Serviço Social da Indústria. Alimente-se Bem com R\$1,00, São Paulo, 8ª ed., Agosto 2004.

SOUZA, Jane Cristina et al. Qualidade Protéica de Multimisturas Distribuídas em Alfenas, Minas Gerais, Brasil. Revista de Nutrição, Campinas, nov./dez. 2006.

STOPPELLI, Illona Maria de Brito Sá; MAGALHÃES, Cláudio Picanço. Saúde e Segurança Alimentar: a questão dos agrotóxicos. Revista de Ciências e Saúde Coletiva, Rio de Janeiro, v. 10, set./dec. 2005.

TORRES, Elizabeth Aparecida Ferraz da Silva et al. Composição Centesimal e Valor Calórico de Alimentos de Origem Animal. Revista de Ciência e Tecnologia de Alimentos, Campinas, v. 20, n. 2, maio/agosto, 2000.

VIANA, Daniela Soares et al. Análise da Dieta Habitual ás Recomendações Nutricionais em Pacientes Atendidos em Consultório Particular. Revista Brasileira de Obesidade, Nutrição e Emagrecimento. São Paulo, v. 1, n. 3, p. 55-59, mai/Jun, 2007.

VITÓRIA. Disponível em: <www.vitoria.es.gov.br/regionais/home.asp $>$ Acesso em 05 fev. 2009.

VIZEU, Vanessa Elias; FEIJÓ, Márcia Barreto da Silva; CAMPOS, Calixto Reinaldo. Determinação da Composição Mineral de Diferentes Formulações de Multimistura. Revista Tecnologia de Alimento. Campinas, v. 25, n.2, p. 254 - 258, abr./jun, 2005. 
Apêndices 


\section{APÊNDICE I - TERMO DE CONCORDÂNCIA DE PARTICIPAÇÃO DA INSTITUIÇÃO}

30 de Setembro de 2008

Para,

Diretoria do Curso Pré-Vestibular Dandara

IImo. Sr ${ }^{\mathrm{a}}$. Diretoria,

Encaminho o pré-projeto de Trabalho de Conclusão do Curso de Pós Graduação em Qualidade em Alimento da aluna Juliana Tavares Nunes, intitulado "Aproveitamento Integral dos Alimentos: Qualidade Nutricional e aceitabilidade das preparações". A aluna, sob orientação da Professora Doutora Raquel Botelho, pretende desenvolver quatro preparações dietéticas de baixo custo e saudáveis. As referidas preparações não proporcionarão nenhum tipo de risco para a saúde do ser humano. No entanto, é preciso testar a aceitabilidade das preparações. A acadêmica do Curso de Pós Graduação em Qualidade em Alimento escolheu os alunos do Curso Pré-Vestibular Dandara para efetuar este teste. Sendo assim, solicitando junto á diretoria do referido Curso a autorização, que permitirá operacionar o trabalho durante os intervalos das aulas.

Aproveito para agradecer, desde já a Diretoria do Curso Pré-Vestibular Dandara para o apoio que prestará a aluna.

Atenciosamente, 


\section{APÊNDICE II - INFORMATIVO DO PROJETO}

Caro (a) Senhor (a),

Está sendo desenvolvida pela acadêmica Juliana Tavares Nunes, celular (27) 9922-1025, do curso de Pós Graduação da Universidade de Brasília, sob orientação da Professora Mestre Raquel Botelho, uma pesquisa sobre "Aproveitamento Integral dos Alimentos: Qualidade Nutricional e a Aceitabilidade das Preparações".

Um dos objetivos desta pesquisa é desenvolver receitas padrões e receitas que utilize os alimentos na sua totalidade e comparar a aceitabilidade das mesmas. Para alcançar estes objetivos, foram desenvolvidas quatro preparações de baixo custo e de alto valor nutricional. No desenvolvimento destas preparações foram utilizados ingredientes e procedimentos isentos de riscos para a saúde humana.

A participação do Sr. (a) nesta pesquisa é voluntária e a avaliação das preparações não determinará nenhum risco ou desconforto. Sua colaboração proporcionará um melhor conhecimento a respeito de Aproveitamento integral dos alimentos.

Cada participante terá direito às informações pertinentes sobre a pesquisa e seus resultados. Será garantida a liberdade de retirada do consentimento a qualquer momento e deixar de participar desta pesquisa sem qualquer prejuízo. As informações obtidas serão analisadas em conjunto com outros participantes, não sendo divulgado a identificação de nenhum dos mesmos.

A referida participação não acarretará gastos da parte dos participantes em qualquer fase do estudo. Não haverá compensação financeira relacionada á sua participação.

Os dados coletados serão somente utilizados para pesquisa e os resultados serão veiculados através de artigos científicos em revistas especializadas e/ou em encontros científicos e congressos, sem nunca tornar possível sua identificação.

Anexo está o consentimento livre e esclarecido para ser assinado caso não tenha ficado qualquer dúvida. 


\section{APÊNDICE III - TERMO DE CONSENTIMENTO LIVRE ESCLARECIDO}

\section{TERMO DE CONSENTIMENTO LIVRE E ESCLARECIDO}

Acredito ter sido suficientemente informado sobre a pesquisa "Aproveitamento Integral dos Alimentos: Qualidade Nutricional e a Aceitabilidade das Preparações".

Foi discutido com a acadêmica do Curso de Pós Graduação em Qualidade em Alimento, Juliana Tavares Nunes, sobre a minha decisão em participar desse estudo. Ficaram claros para mim quais são os propósitos desse estudo, os procedimentos a serem realizados, as garantias de confidencialidade e de esclarecimentos permanentes.

Ficou claro também que a minha participação é isenta de despesas e que tenho garantia do acesso aos resultados e de esclarecer minhas dúvidas a qualquer tempo.

Concordo voluntariamente em participar deste estudo e poderei retirar o meu consentimento a qualquer momento, antes ou durante o mesmo, sem a penalidade ou prejuízo ou perda de qualquer benefício que eu possa ter adquirido.

Data:

Assinatura:

Nome:

$R G$ :

Assinatura das pesquisadoras:

Assinatura da orientadora: 


\section{APÊNDICE IV - FICHA TÉCNICA DO BOLO DE BANANA}

\section{FICHA TÉCNICA DE PREPARAÇÃO}

\section{NOME DA PREPARAÇÃO: Bolo de banana tradicional}

\begin{tabular}{|c|c|c|c|c|c|}
\hline INGREDIENTES & Peso Bruto & $\begin{array}{l}\text { Peso } \\
\text { líquido }\end{array}$ & FC & $\begin{array}{l}\text { Per } \\
\text { capita } \\
\text { líquida }\end{array}$ & Modo de Preparo \\
\hline Banana & $330 \mathrm{~g}$ & $218,54 \mathrm{~g}$ & 1,51 & $10,92 \mathrm{~g}$ & $\begin{array}{l}\text { Descascar as bananas, cortar em rodelas reservando em geladeira. } \\
\text { Separar a clara da gema em um recipiente. }\end{array}$ \\
\hline Ovos & $240 \mathrm{~g}$ & $214,28 \mathrm{~g}$ & 1,12 & $10,71 \mathrm{~g}$ & Bater as claras em neve e reservar na geladeira. \\
\hline Margarina com sal & $45 \mathrm{~g}$ & $45 \mathrm{~g}$ & 1 & $2,25 \mathrm{~g}$ & $\begin{array}{l}\text { Processar na batedeira as gemas, o leite, a margarina, o trigo e } 510 \text { gramas de açúcar até obter } \\
\text { uma massa homogênea. }\end{array}$ \\
\hline Açúcar cristal & $680 \mathrm{~g}$ & $680 \mathrm{~g}$ & 1 & $34 \mathrm{~g}$ & Pré-aquecer o forno em temperatura de $180^{\circ} \mathrm{C}$ \\
\hline Farinha de trigo & $375 \mathrm{~g}$ & $375 \mathrm{~g}$ & 1 & $18,75 \mathrm{~g}$ & $\begin{array}{l}\text { Colocar a massa em uma forma redonda untada com farinha de trigo e margarina. } \\
\text { Deixar no forno a } 180^{\circ} \mathrm{C} \text { por } 40 \text { minutos. }\end{array}$ \\
\hline Leite integral & $400 \mathrm{~g}$ & $400 \mathrm{~g}$ & 1 & $20 \mathrm{~g}$ & Fazer a cobertura da seguinte forma: \\
\hline Limão & $25 \mathrm{~g}$ & $11,36 \mathrm{~g}$ & 2,20 & $0,56 \mathrm{~g}$ & $\begin{array}{l}\text { Derreter em temperatura de } 120^{\circ} \mathrm{C}, 170 \text { gramas de açúcar até formar um caramelo. } \\
\text { Adicionar água aos poucos. }\end{array}$ \\
\hline Fermento em pó & $15 \mathrm{~g}$ & $15 \mathrm{~g}$ & 1 & $0,75 \mathrm{~g}$ & Acrescentar as bananas cortadas em rodelas e o suco do limão. \\
\hline Água & $200 \mathrm{ml}$ & $200 \mathrm{ml}$ & 1 & $10 \mathrm{ml}$ & Após assar o bolo, espalhar a cobertura caramelizada. \\
\hline
\end{tabular}

VET total $=5.160,00 \mathrm{Kcal}$

VET individual $=255,33 \mathrm{Kcal}$

PTN: $3,98 \mathrm{~g}-15,92 \mathrm{Kcal}-6,23 \%$

LIP: $3,37 \mathrm{~g}-30,33 \mathrm{Kcal}-11,88 \%$

CHO: $52,27 \mathrm{~g}-209,08 \mathrm{Kcal}-81,89 \%$

Fibra (porção): $0,65 \mathrm{~g}$

Rendimento: 20 porções

Porção: $70 \mathrm{~g}$

Porção (med. caseira): 01 pedaço médio

Fator de cocção: 0,65 


\section{APÊNDICE V - FICHA TÉCNICA DO BOLO DE CASCA DE BANANA}

\section{NOME DA PREPARAÇÃO: Bolo de casca de banana}

\section{FICHA TÉCNICA DE PREPARAÇÃO}

\begin{tabular}{|c|c|c|c|c|c|}
\hline INGREDIENTES & Peso Bruto & $\begin{array}{l}\text { Peso } \\
\text { líquido }\end{array}$ & FC & $\begin{array}{l}\text { Per capita } \\
\text { líquida }\end{array}$ & Modo de Preparo \\
\hline Banana & $693,54 \mathrm{~g}$ & $693,54 \mathrm{~g}$ & 1 & $34,67 \mathrm{~g}$ & $\begin{array}{l}\text { Descascar as bananas e cortar em rodelas reservando em geladeira as bananas e as cascas. } \\
\text { Separar a clara da gema em um recipiente. }\end{array}$ \\
\hline Ovos & $240 \mathrm{~g}$ & $214,28 \mathrm{~g}$ & 1,12 & $10,71 \mathrm{~g}$ & Bater as claras em neve e reservar na geladeira. \\
\hline Margarina com sal & $45 \mathrm{~g}$ & $45 \mathrm{~g}$ & 1 & $2,25 \mathrm{~g}$ & $\begin{array}{l}\text { Processar no liquidificador as gemas, o leite, a margarina, o trigo e } 340 \text { gramas de açúcar e as } \\
\text { cascas até obter uma massa homogênea. }\end{array}$ \\
\hline Açúcar cristal & $510 \mathrm{~g}$ & $510 \mathrm{~g}$ & 1 & $25,5 \mathrm{~g}$ & Verter a massa em uma vasilha, acrescentar a farinha de rosca, farinha de trigo e mexer com uma \\
\hline Farinha de trigo & $125 \mathrm{~g}$ & $125 \mathrm{~g}$ & 1 & $6,25 \mathrm{~g}$ & Pré-aquecer o forno em temperatura de $180^{\circ} \mathrm{C}$. \\
\hline Leite integral & $400 \mathrm{~g}$ & $400 \mathrm{~g}$ & 1 & $20 \mathrm{~g}$ & $\begin{array}{l}\text { Misturar na massa delicadamente as claras em neve e o fermento em pó. } \\
\text { Colocar a massa em uma forma redonda untada com farinha de trigo e margarina. }\end{array}$ \\
\hline Farinha de rosca & $220 \mathrm{~g}$ & $220 \mathrm{~g}$ & 1 & $11 \mathrm{~g}$ & $\begin{array}{l}\text { Deixar no forno a } 180^{\circ} \mathrm{C} \text { por } 40 \text { minutos. } \\
\text { Fazer a cobertura da seguinte forma: }\end{array}$ \\
\hline Limão & $25 \mathrm{~g}$ & $11,36 \mathrm{~g}$ & 2,20 & $0,56 \mathrm{~g}$ & $\begin{array}{l}\text { Derreter em temperatura de } 120 \text { ㄷ, } 170 \text { gramas de açúcar até formar um caramelo. } \\
\text { Adicionar água aos poucos. }\end{array}$ \\
\hline Fermento em pó & $45 \mathrm{~g}$ & $45 \mathrm{~g}$ & 1 & $0,99 \mathrm{~g}$ & Acrescentar as bananas cortadas em rodelas e o suco do limão. \\
\hline Água & $200 \mathrm{ml}$ & $200 \mathrm{ml}$ & 1 & $10 \mathrm{ml}$ & Após assar o bolo, espalhar a cobertura caramelizada. \\
\hline
\end{tabular}

\section{VET total $=4.921,20 \mathrm{Kcal}$}

VET individual $=246,06 \mathrm{Kcal}$

PTN: $4,32 \mathrm{~g}-17,28 \mathrm{Kcal}-7,02 \%$

LIP: $3,38 \mathrm{~g}-30,42 \mathrm{Kcal}-12,35 \%$

CHO: $49,59 \mathrm{~g}-198,36 \mathrm{Kcal}-80,63 \%$

Fibra (porção): $1,35 \mathrm{~g}$
Rendimento: 20 porções

Porção: $70 \mathrm{~g}$

Porção (med. caseira): 01 pedaço pequeno

Fator de cocção: 0,57 
APÊNDICE VI - FICHA TÉCNICA DO SUCO DE ACEROLA

\section{FICHA DE TÉCNICA DE PREPARAÇÃO}

NOME DA PREPARAĈ̃̃: Suco de acerola

\begin{tabular}{|c|c|c|c|c|c|}
\hline INGREDIENTES & $\begin{array}{l}\text { Peso } \\
\text { Bruto }\end{array}$ & $\begin{array}{l}\text { Peso } \\
\text { líquido }\end{array}$ & FC & $\begin{array}{l}\text { Per capita } \\
\text { líquida }\end{array}$ & Modo de Preparo \\
\hline Acerola & $500 \mathrm{~g}$ & $500 \mathrm{~g}$ & 1 & $100 \mathrm{~g}$ & Misturar no liquidificador a água, o açúcar e a acerola. \\
\hline Açúcar & $170 \mathrm{~g}$ & $170 \mathrm{~g}$ & 1 & $34 \mathrm{~g}$ & Bater por aproximadamente 3 minutos. \\
\hline Água & $1000 \mathrm{ml}$ & $1000 \mathrm{ml}$ & 1 & $200 \mathrm{ml}$ & 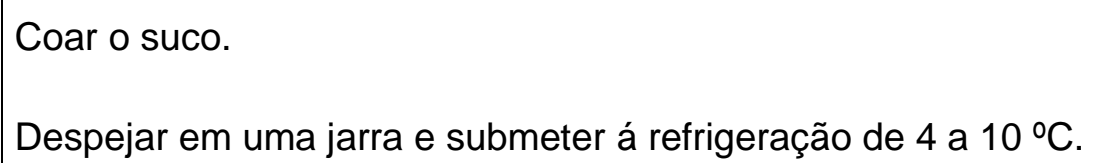 \\
\hline
\end{tabular}

VET total $=812,70 \mathrm{Kcal}$

VET individual $=162,54 \mathrm{Kcal}$

PTN: $0,60 \mathrm{~g}-2,4 \mathrm{Kcal}-1,48 \%$

LIP: $0,30 \mathrm{~g}-2,70 \mathrm{Kcal}-1,66 \%$

CHO: $39,36 \mathrm{~g}-157,44 \mathrm{Kcal}-96,86 \%$

Fibra (porção): $0,70 \mathrm{~g}$
Rendimento: 05 porções

Porção: $300 \mathrm{ml}$

Porção (med. caseira): 01 copo médio 
ANEXO VII - FICHA TÉCNICA DO SUCO DE ACEROLA, CENOURA E COUVE

FICHA TÉCNICA DE PREPARAÇÃO

NOME DA PREPARAČ̃A: Suco de acerola, cenoura e couve

\begin{tabular}{|c|c|c|c|c|c|}
\hline INGREDIENTES & Peso Bruto & $\begin{array}{l}\text { Peso } \\
\text { líquido }\end{array}$ & FC & $\begin{array}{c}\text { Per } \\
\text { capita } \\
\text { líquida }\end{array}$ & Modo de Preparo \\
\hline Acerola & $500 \mathrm{~g}$ & $500 \mathrm{~g}$ & 1 & $100 \mathrm{~g}$ & \multirow{5}{*}{$\begin{array}{l}\text { Misturar no liquidificador a água, o açúcar, a acerola, a cenoura e a couve. } \\
\text { Bater por aproximadamente } 4 \text { minutos. } \\
\text { Coar o suco. } \\
\text { Despejar em uma jarra e submeter á refrigeração de } 4 \text { a } 10 \text { ㄷ. }\end{array}$} \\
\hline Cenoura & $240 \mathrm{~g}$ & $240 \mathrm{~g}$ & 1 & $48 \mathrm{~g}$ & \\
\hline Couve & $20 \mathrm{~g}$ & $20 \mathrm{~g}$ & 1 & $4 \mathrm{~g}$ & \\
\hline Açúcar & $170 \mathrm{~g}$ & $170 \mathrm{~g}$ & 1 & $34 \mathrm{~g}$ & \\
\hline Água & $1000 \mathrm{ml}$ & $1000 \mathrm{ml}$ & 1 & $200 \mathrm{ml}$ & \\
\hline
\end{tabular}

VET total $=909,45 \mathrm{Kcal}$

VET individual $=181,89 \mathrm{Kcal}$

PTN: $1,33 \mathrm{~g}-5,32 \mathrm{Kcal}-2,92 \%$

LIP: $0,41 \mathrm{~g}-3,69 \mathrm{Kcal}-2.03 \%$

CHO: $43,22 \mathrm{~g}-172,88 \mathrm{Kcal}-95,05 \%$

Fibra (porção): $1,65 \mathrm{~g}$
Rendimento: 5 porções

Porção: $300 \mathrm{ml}$

Porção (med. caseira): 01 copo médio 


\section{APÊNDICE VIII - QUESTIONÁRIO DE ACEITABILIDADE}

\section{QUESTIONÁRIO DE ACEITACÃO}

1. Dados pessoais: Idade: 2.Qual a sua renda familiar?
Data da coleta:

Número do questionário:

3. Informação Residencial:

Bairro:

Município:

4. Ocupação:

$\begin{array}{ll}\text { a) Só trabalha ( ) } & \text { c) Estuda e Trabalha ( ) }\end{array}$

b) Só Estuda ( )

d) Estuda somente no Projeto Dandara ( )

5. Você tem hábito de cozinhar em casa?
( ) Sim
( ) Não

6. Quem costuma preparar suas refeições em casa?

7. Você já ouviu falar em Aproveitamento Integral dos Alimentos? O quê você entende sobre assunto?

8. Por favor, prove as amostras e utilizando a escala abaixo identifique o quanto você gostou ou desgostou do produto. Marque a posição da escala que melhor reflita o seu julgamento.

Bolo

5. Gostei muito

4. Gostei moderadamente

3. Indiferente

2. Desgostei moderadamente

1. Desgostei muito

9. Responda:
Suco

5. Gostei muito

4. Gostei moderadamente

3. Indiferente

2. Desgostei moderadamente

1. Desgostei muito

A) Qual (s) ingrediente (s) do Bolo que você consegue identificar?

B) Qual (s) ingrediente (s) do Suco que você consegue identificar?

C) Qual (s) preparação (s) você gostou?

$$
\begin{array}{lll}
\text { 1.( ) Bolo } & \text { 2.( ) Suco } & \text { 3. ( ) Bolo e o Suco }
\end{array}
$$

D) Você faria essa (s) receita (s) em casa? Porquê?

E) Eventualmente, você utilizaria essa (s) preparação (s) para substituir o seu lanche da tarde?

F) Quanto você imagina que seja o custo das preparações?

1. Bolo

2. Suco 


\section{APÊNDICE IX - Informativo do bolo de banana}

\section{BOLO DE BANANA}

\begin{tabular}{|c|c|c|}
\hline Ingredientes & Medidas caseiras & Preço \\
\hline Banana sem casca & 5 unidades & $\mathrm{R} \$ \quad 0,80$ \\
\hline Ovos & 4 unidades & $\mathrm{R} \$ \mathbf{0 , 5 0}$ \\
\hline Margarina com sal & 3 colheres de sopa & $R \$ \quad 0,30$ \\
\hline Açúcar cristal & 4 xícaras & $\mathrm{R} \$ \mathbf{0 , 8 0}$ \\
\hline Farinha de trigo & 3 xícaras & $\mathrm{R} \$ \mathbf{0 , 3 0}$ \\
\hline Leite integral & 2 xícaras & $R \$ \quad 0,60$ \\
\hline Limão & 1 unidade média & $\mathrm{R} \$ \quad 0,10$ \\
\hline Fermento em pó & 1 colher de sopa & $R \$ \quad 0,20$ \\
\hline & & $\mathrm{R} \$ \mathbf{3 , 6 0}$ \\
\hline
\end{tabular}

Valores de acordo com a cesta básica referente ao mês de setembro 2008

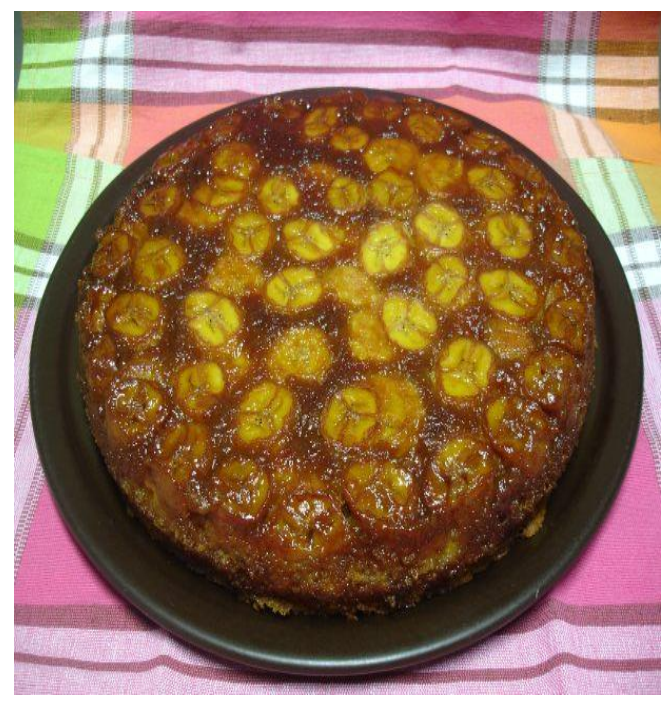

Tempo de preparo: $1 \mathrm{~h}$ e $10 \mathrm{~min}$.

Rendimento: 20 porções de $70 \mathrm{~g}$

Custo da preparação: $R \$ 3,60$

Valor calórico da porção: 255,33 kcal

Todos os recipientes e utensílios foram sanitizado com uma solução clorada a 200ppm durante 15 minutos. As bananas foram lavadas em água corrente e logo em seguida, as mesmas foram descascadas e cortadas. Os ovos foram sanitizados a solução a 150 ppm, durante 5 minutos, logo após separou-se a clara da gema em um recipiente. As claras foram batidas em neve e reservadas na geladeira. As gemas, o leite, a margarina, três xícaras de açúcar e o trigo foram processados na batedeira até obter uma massa homogênea. Em seguida misturou-se na massa delicadamente as claras e neve e o fermento em pó. A massa foi despejada em uma assadeira untada com farinha de trigo e margarina e levada ao forno a $180{ }^{\circ} \mathrm{C}$ durante 30 minutos. Para a cobertura o 1 xícara de açúcar foi caramelizado a temperatura de $120^{\circ} \mathrm{C}$ e aos poucos acrescentava-se a água, em seguida foi adicionado as bananas cortadas em rodelas e o suco do limão e deixou-se cozinhar durante 5 minutos, obtendo assim uma banana caramelizada. Após assada a massa, a mesma foi coberta pela banana caramelizada. 


\section{APÊNDICE X - Informativo do bolo de casca de banana}

\section{BOLO DE CASCA DE BANANA}

\begin{tabular}{|l|l|r|}
\hline Ingredientes & Medidas caseiras & Preço \\
\hline Banana com casca & 10 unidades & $\mathrm{R} \$ 1,50$ \\
\hline Ovos & 4 unidades & $\mathrm{R} \$ 0,50$ \\
\hline Margarina com sal & 3 colheres de sopa & $\mathrm{R} \$ 0,30$ \\
\hline Açúcar cristal & 3 xícaras & $\mathrm{R} \$ 0,60$ \\
\hline Farinha de rosca & 2 xícaras & $\mathrm{R} \$ 0,90$ \\
\hline Farinha de trigo & 1 xícara & $\mathrm{R} \$ 0,10$ \\
\hline Leite integral & 2 xícaras & $\mathrm{R} \$ 0,60$ \\
\hline Limão & 1 unidade média & $\mathrm{R} \$ 0,10$ \\
\hline Fermento em pó & 3 colheres de sopa & $\mathrm{R} \$ 0,60$ \\
\hline & & $\mathbf{R} \mathbf{5 , 2 0}$ \\
\cline { 3 - 3 } & &
\end{tabular}

Valores de acordo com a cesta básica referênte ao mês de setembro 2008

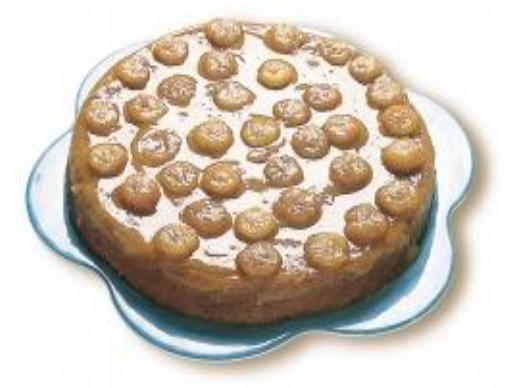

Tempo de preparo: $1 \mathrm{~h}$ e $10 \mathrm{~min}$.

Rendimento: 20 porções de $70 \mathrm{~g}$

Custo da preparação: $R \$ 5,20$

Valor calórico da porção: $246,06 \mathrm{kcal}$

Todos os recipientes e utensílios foram sanitizado com uma solução clorada a 200ppm durante 15 minutos. As bananas foram lavadas em água corrente e escovadas, logo em seguida, as mesmas foram descascadas e cortadas. Os ovos foram sanitizados a solução a 150 ppm, durante 5 minutos, logo após separou-se a clara da gema em um recipiente. As claras foram batidas em neve e reservadas na geladeira. As gemas, o leite, a margarina, duas xícaras de açúcar e as cascas de bananas foram liquidificadas até obter uma massa homogênea, em seguida foi despejada em um recipiente a acrescentado a farinha de rosca e a farinha de trigo até a massa ficar homogênea. Ao final misturou-se na massa delicadamente as claras e neve e o fermento em pó. Em seguida a massa foi despejada em uma assadeira untada com farinha de trigo e margarina e levada ao forno a $180^{\circ} \mathrm{C}$ durante 40 minutos. Para a cobertura uma xícara de açúcar foi caramelizado a temperatura de 120 ${ }^{\circ} \mathrm{C}$ e aos poucos acrescentava-se a água, em seguida foi adicionado as bananas cortadas em rodelas $\mathrm{e}$ o suco do limão e deixou-se cozinhar durante 5 minutos, obtendo assim uma banana caramelizada. Após assada a massa, a mesma foi coberta pela banana caramelizada. 


\section{APÊNDICE XI - Informativo do suco de acerola}

\section{SUCO DE ACEROLA}

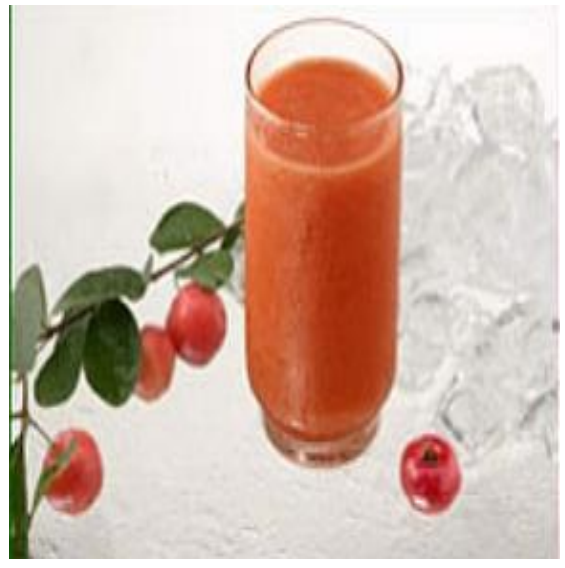

\begin{tabular}{|l|l|l|}
\hline Ingredientes & Medidas caseiras & Preço \\
\hline Acerola (Polpa) & $1 / 2$ kilo & $\mathrm{R} \$ 2,50$ \\
\hline Açúcar cristal & 1 xícara & $\mathrm{R} \$ 0,20$ \\
\hline Àgua & 1 litro & $\mathrm{R} \$ 1,60$ \\
\hline \multicolumn{2}{l|}{} & $\mathbf{R} \mathbf{4 , 3 0}$ \\
&
\end{tabular}

Valores de acordo com a cesta básica referente ao mês de setembro 2008

Tempo de preparo: 35 minutos.

Rendimento: 5 porções de $300 \mathrm{ml}$

Custo da preparação: $\mathrm{R} \$$ 4,30

Valor calórico da porção: 162,54 kcal

Todos os utensílios foram sanitizados com uma solução clorada a 200 ppm durante 15 minutos. As acerolas foram sanitizadas a $150 \mathrm{ppm}$, deixados por 5 minutos e lavadas em água potável. Em seguida, foram liquidificados a água, acerola e o açúcar por 3 minutos, e logo após o suco foi coado e despejado em uma jarra e submetido á refrigeração de 4 a 10 ㄷ. 


\section{SUCO DE ACEROLA, CENOURA E COUVE}

\begin{tabular}{|c|c|c|}
\hline Ingredientes & Medidas caseiras & Preço \\
\hline Acerola (Polpa) & $1 / 2$ kilo & $R \$ 2,50$ \\
\hline Cenoura & 2 unid. Médias & $\mathrm{R} \$ \mathbf{0 , 5 0}$ \\
\hline Couve & 1 folha média & $\mathrm{R} \$ 0,20$ \\
\hline Açúcar cristal & 1 xícara & $\mathrm{R} \$ 0,20$ \\
\hline Água & 1 litro & $\mathrm{R} \$ 1,60$ \\
\hline
\end{tabular}

Valores de acordo com a cesta básica referente ao mês de setembro 2008.

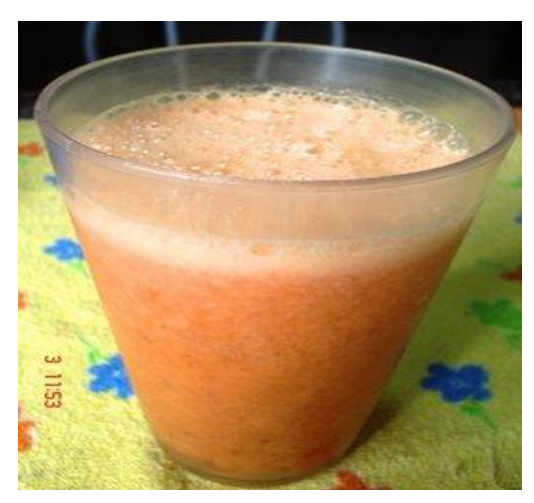

Tempo de preparo: 35 minutos.

Rendimento: 5 porções de $300 \mathrm{ml}$ Custo da preparação: $\mathrm{R} \$ \mathrm{5}, 00$

Valor calórico da porção: 181,89 kcal

Todos os utensílios foram sanitizados com uma solução clorada a 200 ppm durante 15 minutos. As acerolas, cenoura e couve foram sanitizadas a 150 ppm, deixados por 5 minutos e lavadas em água potável. Em seguida, foram liquidificados a água, acerola, cenoura, couve e o açúcar por 4 minutos, em seguida o suco foi coado e despejado em uma jarra e submetido á refrigeração de 4 a 10 ㄷ․ 